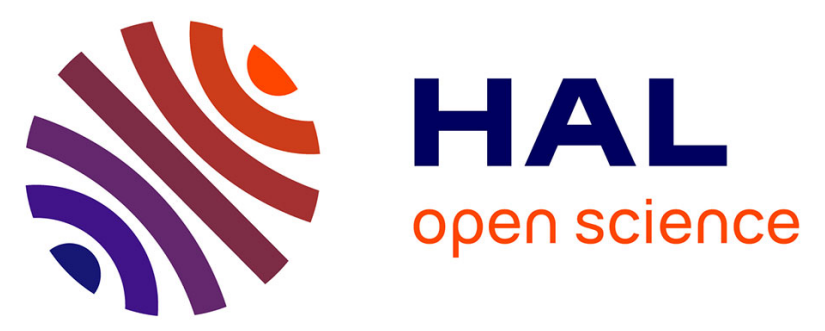

\title{
Pathway-27 : Etude Pilote sur les effets de substances bioactives en lien avec des marqueurs du Syndrome Métabolique
}

Julien Amat, Corinne Malpuech Brugere, A. Blot, N. Meunier, Noël Cano, Jean-Louis Sébédio, Alessandra Bordoni

\section{To cite this version:}

Julien Amat, Corinne Malpuech Brugere, A. Blot, N. Meunier, Noël Cano, et al.. Pathway-27 : Etude Pilote sur les effets de substances bioactives en lien avec des marqueurs du Syndrome Métabolique. 8. Journée Scientifique du CRNH Auvergne, Nov 2015, Clermont-Ferrand, France. 2015, 8ème Journée Scientifique du CRNH Auvergne. hal-01263586

\section{HAL Id: hal-01263586 https://hal.science/hal-01263586}

Submitted on 3 Jun 2020

HAL is a multi-disciplinary open access archive for the deposit and dissemination of scientific research documents, whether they are published or not. The documents may come from teaching and research institutions in France or abroad, or from public or private research centers.
L'archive ouverte pluridisciplinaire HAL, est destinée au dépôt et à la diffusion de documents scientifiques de niveau recherche, publiés ou non, émanant des établissements d'enseignement et de recherche français ou étrangers, des laboratoires publics ou privés. 


\section{$\because \mathrm{CRNH} S$}

CENTRES DE RECHERCHE

EN NUTRITION HUMAINE
iCRNH

CENTRE DE RECHERCHE

EN NUTRITION HUMAINE

AUVERGNE

\section{8ème Journée Scientifique du CRNH Auvergne}

Pôle Physique des Cézeaux, 26 novembre 2015

Organisation : Bureau CRNH Auvergne
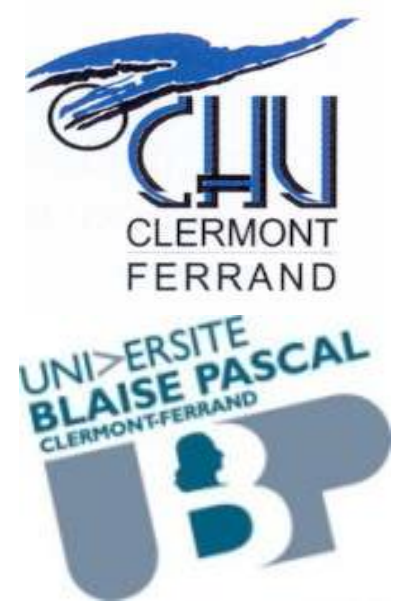
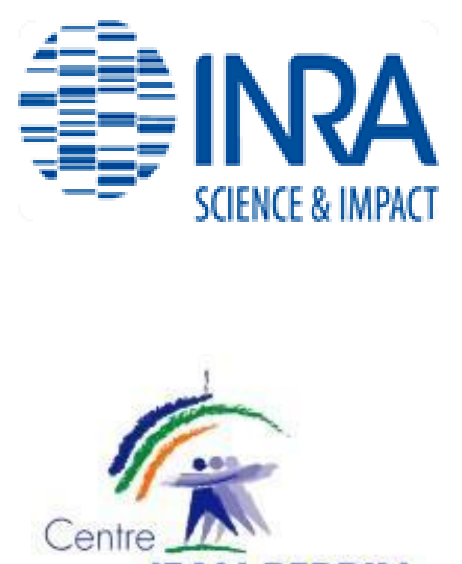

JEAN PERRIN

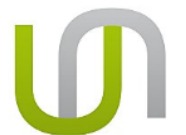

UdA

州 Inserm

Institut national de la santé et de la recherche medicale 



\section{Programme}

8h00 Accueil, installation des posters

9h00 Introduction

9h15 - $10 \mathrm{~h} 00 \quad$ Tissus osseux et musculaire (0. LE BACQUER)

C01 Sarcopénie et médication : données expérimentales obtenues chez le rat soumis à un traitement chronique au paracétamol.

C Mast, I Savary-Auzeloux, D Rémond, C Pouyet, D Centeno, G. Voyard, L. Combaret, D Dardevet, I Papet

CO2 Caractéristiques de l'architecture musculaire et de l'activation nerveuse chez l'adolescente obèse.

S Garcia-Vicencio, V Martin, V Kluka, C Cardenoux, A-G Jegu, A-V Fourot, E Coudeyre, S Ratel

C03 La résistance anabolique lors d'une surnutrition lipidique n'est pas levée par un apport protéique supplémentaire chez le rat âgé.

A Carayon, J Salles, C Giraudet, V Patrac, A Berry, O Le Bacquer, JP Rigaudière, C Domingues-Faria, A Chanet, V Martin, S Ratel, S Walrand, Y Boirie, $\underline{\text { C Guillet }}$

\section{0:00- 10:30 pause}

\section{$10 \mathrm{~h} 30-11 \mathrm{~h} 15 \quad$ Cardiométabolique (C. GLADINE)}

CO4 Des protéines sanguines marqueurs de prédiction du syndrome métabolique ? Une étude cas-témoins nichée dans la cohorte Haguenau.

J Bertrand, M Pétéra, A Fernandes, J Matta, C Lévy-Marchal, S Czernichow, E Pujos-Guillot, B Comte

C05 Effet d'un programme d'activité physique intermittent de haute intensité sur la perte de masse grasse abdominale chez la femme DT2 ménopausée.

F Maillard, L Metz, S Penando, S Rousset, Y Boirie, M Duclos, N Boisseau.

C06 Contraintes de cisaillement : modulateur des effets vasoprotecteur des polyphénols ?

L-E Monfoulet, S Mercier, D Milenkovic, C Morand

$11 \mathrm{~h} 15-12 \mathrm{~h} 05$

Conférence : Frédéric COSTES (CHU de Clermont-Ferrand)

"Retentissement musculaire de l'hypoxie »

12:15 - 13:30 Repas 
$13 \mathrm{~h} 30-14 \mathrm{~h} 30 \quad$ Posters

\section{4h30 - 15h15 Tractus Gastro-Intestinal (G. JUBELIN)}

CO7 Implication de la communauté sulfato-réductrice dans la genèse de l'hypersensibilité viscérale chez les sujets atteints du Syndrome de l'Intestin Irritable.

L Crouzet, C Habouzit, E Gaultier, C Del'homme, E Delmas, M Dapoigny, J Fioramonti, A BernalierDonadille

C08 Les bactéries du microbiote intestinal : de nouveaux acteurs impliqués dans le cancer colorectal. G Dalmasso, J Delmas, M Bonnet, N Barnich, R Bonnet

C09 Isolement de Methanomethylophilus alvus gen. nov., sp. nov., archée méthanogène métabolisant le précurseur de l'agent plasmatique proathérogène TMAO.

N Gaci, W Ben Hania, G Borrel, P-P Chaudhary, M-L Fardeau, W Tottey, M Alric, P-W O'Toole, B Ollivier, J-F Brugère

\section{5h15-16h00 Cancer (A. ROSSARY)}

C010 Identification de perturbateurs chimiques des LIVER X RECEPTORS impliqués dans le cancer de la prostate.

A Fouache, M Poirot, S Baron, D-H Volle, A Trousson, J-M Lobaccaro

C011 Influence de la leptine, de l'IL6 et de traitements anti-cancéreux sur la prolifération de cellules souches cancéreuses.

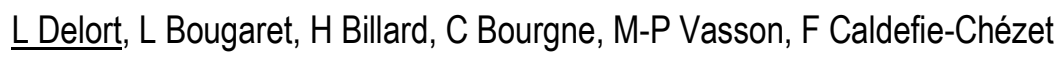

C012 Modifications des histones H3 dans les différents sous-types moléculaires du cancer du sein.

G Judes, A Dagdemir, S Karsli-Ceppioglu, A Lebert, M Ngollo, Y-J Bignon, F Penault-Llorca, D BernardGallon 


\section{POSTERS}

\section{Modérateurs (G. GARRAIT - F. CAPEL)}

P1 Identification de bio-marqueurs prédictifs et précoces de l'ostéoporose : approche préclinique. Z Tatar, F Wauquier, L Léotoing, M-J Davicco, M Soubrier, Y Wittrant, V Coxam

P2 Effect of anthocyanins and their microbiota metabolites on monocyte adhesion to endothelial cells at physiologically relevant concentrations.

I Krga, S Mercier, L-E Monfoulet, C.Morand, A Konic-Ristic, D Milenkovic

P3 Comparative study of EHEC survival and virulence under adult and infant simulated digestive conditions.

R Charlène, C Charlotte, W Galia, O Le Goff, J Thevenot, S Chalancon, M Alric, D Thevenot-Sergentet, F Leriche, V Livrelli, T-V de Wiele, S Blanquet-Diot

P4 Régulation de la marque H3K27me3 par la déméthylase d'histone JMJD3 et la méthyltransférase EZH2 dans les cancers de la prostate.

M Daures, M Ngollo, G Judes, K Rifaï, J-L Kemeny, F Penault-Llorca, Y-J Bignon, L Guy, D Bernard-Gallon

P5 Etude de l'impact de composés circulants issus de la consommation d'huile d'olive, vierge ou raffinée, enrichie ou non en Vitamine $D$, sur la biologie des cellules osseuses.

F Wauquier, M-J Davicco, P Lebecque, C Tagliaferri, A Dhaussy, A Huertas, S Walrand, Y Wittrant, V Coxam

P6 Bioactive oxylipins derived from DHA: neuroprostanes contribute to the anti-inflammatory action of DHA through the inhibition of NFKB and independently to PPAR $\gamma$.

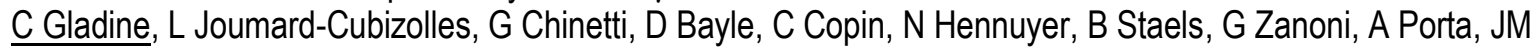
Galano, C Oger, A Mazur, T Durand

P7 EHEC interactions with Peyers patches and antagonistic effect of the probiotic yeast Saccharomyces cerevisiae.

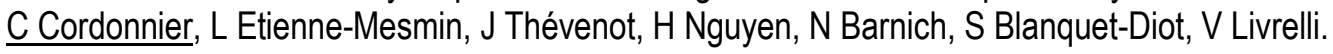

P8 La propolis régule la survie des cellules LNCaP en culture.

N Zabaiou, A Fouache, S Baron, D-H Volle, A Trousson, M Lahouel, J-M Lobaccaro

P9 En situation de catabolisme musculaire, les protéines de lactosérum ne permettent de contrecarrer, que transitoirement, la résistance anabolique.

M Jarzaguet, A Revel, C Migné, I Savary-Auzeloux, D Rémond, D Dardevet

P10 Exosomes: New mediators of host response to Crohn's disease-associated adherent-invasive Escherichia coli J Carrière, A Bretin, N Barnich, A Darfeuille-Michaud, H-T-T Nguyen

P11 Mise en évidence de l'interaction TIP60-H3K4ac dans le cancer sporadique du sein. K Rifai, G Judes, A Lebert, Y-J Bignon, F Penault-Llorca, D Bernard-Gallon

P12 Combinatorial effects of western diet and adherent-invasive $E$. coli infection on intestinal inflammation A Agus, J Denizot, J Thevenot, M Martinez-Medina, S Massier, P Sauvanet, A Bernalier-Donadille, S Denis, P Hofman, R Bonnet, E Billard, N Barnich

P13 FoodComEx: une chimiothèque internationale pour les composés dérivés de l'alimentation.

D Wishart, C Weinert, E pujos Guillot, M Ulaszewska, F Giacomoni, F Mattivi, M Urpi-Sarda, C Andres-Lacueva, S-

E Kulling, LO Dragsted, $\underline{\text { C Manach }}$ 
P14 Impact d'une dysbiose intestinale sur l'hypersensibilité viscérale d'origine colique en modèle murin. A Lashermes, S Miquel, R Martin-Rosique, A Gelot, N Barnich, A Darfeuille-Michaud, A Eschalier, D Ardid, M Thomas, P Langella, F-A Carvalho,

P15 PhytoHub : une base de données pour les études métabolomiques sur les bioactifs végétaux. F Giacomoni, Y Fillâtre, J-A Rothwell, R Eisner, E Pujos-Guillot, C Knox, C Manach

P16 Etude clinique : Expression des canaux ioniques Cav et ASIC dans la muqueuse colique des patients atteints de rectocolite hémorragique : étude cas / témoins.

L Boudieu, J Scanzi, A Buisson, M Goutte, A Gelot, M Dapoigny, D Ardid, F-A Carvalho

P17 Effect of acute consumption Passiflora setacea juice on the monocyte adhesion to endothelial cells: a validation ex vivo study.

I Duarte, C Morand, D Milenkovic, L Monfoulet, L Pineli, A-M Costa

P18 Vascular and Nutrigenomic effects of grapefruit flavanones consumption: A RCT in post-menopausal women. V Habauzit, D Milenkovic, M-AVerny, N Barber-Chamoux, C Bobby, A Mazur, C Dubray, C Morand

P19 DHA-supplementation prior to fasting prevents muscle atrophy in mice.

C Deval, F Capel, B Laillet, C Polge, D Béchet, D Taillandier, D Attaix, L Combaret

P20 Pathway-27 : Etude Pilote sur les effets de substances bioactives en lien avec des marqueurs du Syndrome Métabolique.

J Amat, C Malpuech-Brugère, A Blot, N Meunier, N Cano, J-L Sébédio, A Bordoni

Au titre du consortium Pathway- 27 Grant agreement no. 3118761

P21 L'EPA prévient l'insulino-résistance et l'intolérance au glucose chez la souris sous régime hyperlipidique et hypersucré.

A Pinel, J-P Rigaudière, B Laillet, E Pitois, C Jouve, F Capel, B Morio 
COMMUNICATIONS ORALES 


\title{
C01
}

\section{Sarcopénie et médication: données expérimentales obtenues chez le rat soumis à un traitement chronique au paracetamol}

\author{
C Mast ${ }^{(1,2)}$, I Savary-Auzeloux ${ }^{(1,2)}$, D Rémond ${ }^{(1,2)}$, C Pouyet ${ }^{(3)}$, D Centeno ${ }^{(3)}$, \\ G Voyard $^{(4)}$, L Combaret ${ }^{(1,2)}$, D Dardevet ${ }^{(1,2)}$, I Papet $^{(1,2)}$
}

(1) Clermont Université, Université d'Auvergne, Unité de Nutrition Humaine, BP 10448, F-63000

CLERMONT-FERRAND

(2) INRA, UMR 1019, UNH, CRNH Auvergne, F-63000 CLERMONT-FERRAND

(3) Plateforme d'Exploration du Métabolisme, INRA, Centre Auvergne-Rhône-Alpes, UMR 1019 Nutrition Humaine, F-63122 SAINT-GENES-CHAMPANELLE

(4) Clermont Université, Université Blaise Pascal, Institut de Chimie de Clermont-Ferrand, équipe photochimie, BP 10448, F-63000 CLERMONT-FERRAND

\section{Isabelle.Papet@clermont.inra.fr}

La sarcopénie peut résulter, entre autres, d'un défaut de disponibilité en un seul acide aminé au niveau musculaire. La fourniture de cystéine au muscle pourrait être réduite par la prise chronique de paracétamol. En effet, cet acide aminé est consommé par le foie pour produire le sulfate et le glutathion, qui sont nécessaires à la détoxication de ce médicament. L'effet prosarcopéniant potentiel du paracétamol a été testé chez le rat âgé.

Quatorze rats Wistar mâles âgés de 22 mois ont reçu 3 cures de paracétamol ( $1 \%$ du régime) de 2 semaines espacées de 2 semaines sans. Les rats traités au paracétamol ont été comparés à 10 rats avant traitement et 11 rats non traités, consommant la même quantité de régime que ceux traités (pair-fed). La cystéine, le glutathion et la vitesse de synthèse des protéines ont été quantifiés.

La prise alimentaire des rats traités au paracétamol a diminué de $23-33 \%$ pendant les cures, induisant une perte de poids corporel de $8 \%$. Le paracétamol a réduit le glutathion hépatique de $51 \%$, les concentrations plasmatiques en cystéine et glutathion de $28 \%$ par rapport au groupe pair-fed, traduisant un déficit en cystéine. Ceci s'est accompagné d'une chute de la synthèse des protéines musculaires de $15 \%$ dans le muscle gastrocnemius et d'une atrophie des muscles de la patte arrière de $11 \%$. Comparée aux rats témoins, la masse de ces muscles a été réduite de $22 \%$ par le traitement au paracétamol.

Les résultats obtenus chez le rat âgé ayant des apports alimentaires réduits sont en faveur d'une réduction de la disponibilité en cystéine pour le muscle et d'un effet pro-sarcopéniant des traitements répétés au paracétamol. Cet effet reste à tester chez les personnes âgées mangeant peu et recevant des cures répétées de paracétamol pour soulager leurs douleurs chroniques d'intensité faible à modérée. 


\title{
$\mathrm{CO2}$
}

\section{Caractéristiques de l'architecture musculaire et de l'activation nerveuse chez l'adolescente obèse}

\author{
$\underline{\text { S Garcia-Vicencio }}{ }^{(1)}$, V Martin ${ }^{(1)}$, V Kluka ${ }^{(1)}$, C Cardenoux ${ }^{(2)}$, A-G Jegu ${ }^{(2)}$, AV Fourot ${ }^{(3)}$, \\ E Coudeyre ${ }^{(2,4,5)}$, S Ratel ${ }^{(1)}$ \\ (1) Clermont Université, Université Blaise Pascal, CRNH Auvergne, EA 3533, Laboratoire des \\ adaptations Métaboliques à l'Exercice en conditions Physiologiques et Pathologiques (AME2P), \\ BP 10448, F-63000 Clermont-Ferrand, France \\ (2) Centre Hospitalier Universitaire (CHU), Clermont-Ferrand, France \\ (3) MECSS Tza Nou, La Bourboule, France \\ (4) INRA, (UNH, UMR 1019), CRNH Auvergne, Clermont-Ferrand, France \\ (5) Clermont Université, Université d'Auvergne, Clermont-Ferrand, France
}

sebastian.garciavicencio@gmail.com

Le but de cette recherche était de vérifier l'hypothèse selon laquelle l'excès de masse corporelle supporté par les adolescentes obèses pourrait agir comme un stimulus chronique d'entraînement générant des adaptations neuromusculaires favorables (e.g, une augmentation du niveau d'activation volontaire des unités motrices (NA) et de l'Angle de Pennation (AP)), sans modification des dimensions musculaires (e.g, Surface de Section Transversale Anatomique (ACSA) et Epaisseur Musculaire (EM)) par rapport à des adolescentes saines. Les caractéristiques de l'architecture musculaire des muscles Extenseurs du Genou (EG) et des Fléchisseurs Plantaires (FP) ont été évaluées, in vivo, chez 12 adolescentes normopondérées et 12 obèses (12-15 ans). Le NA a été évalué grâce à la technique de la secousse surimposée au cours de contractions maximales volontaires isométriques. Enfin la masse maigre segmentaire a été évaluée par DXA. Les résultats ont révélé des valeurs d'AP ( $p$ $<0,05), E M(p<0,001), A C S A(p<0,01)$ et de masse maigre segmentaire supérieures $(p<0,001)$ chez les adolescentes obèses pour les EG et FP. De plus, nous avons observé que le moment maximal (MM) isométrique absolu était plus élevé chez les adolescentes obèses pour les $E G$ $(224,6 \pm 39,5$ N.m vs. $135,7 \pm 32,7$ N.m; $p<0.001)$ et pour les FP $(73,3 \pm 16,5$ N.m vs. 44,5 \pm 6,2 N.m; $p<0.001)$. Le MM spécifique des FP était significativement supérieur dans le groupe obèse pour les FP ( $p<0.05)$, mais pas pour EG. Finalement, nous avons observé un NA des $E G$ et FP plus élevé $(p<0.001)$ chez les adolescentes obèses. Ces résultats suggèrent que l'excès de masse corporelle supporté par les adolescentes obèses pourrait agir comme un stimulus chronique générant des adaptations neuromusculaires favorables, comparables à celles observées après un entraînement en force chez le sujet sain. 


\title{
$\mathrm{CO3}$
}

\section{La résistance anabolique lors d'une surnutrition lipidique n'est pas levée par un apport protéique supplémentaire chez le rat âgé.}

\author{
A Carayon ${ }^{(1,2)}$, J Salles ${ }^{(1,2)}$, C Giraudet ${ }^{(1,2)}$, V Patrac ${ }^{(1,2)}$, A Berry ${ }^{(1,2)}$, O Le Bacquer ${ }^{(1,2)}$, \\ JP Rigaudière ${ }^{(1,2)}$, C Domingues-Faria ${ }^{(1,2)}$, A Chanet ${ }^{(1,2)}$, V Martin ${ }^{(3)}$, S Ratel ${ }^{(3)}$, \\ S Walrand $^{(1,2)}$, Y Boirie ${ }^{(1,2)}$, C Guillet $^{(1,2)}$
}

(1) Clermont Université, Université d'Auvergne, Unité de Nutrition Humaine, BP 10448, F-63000

Clermont-Ferrand

(2) INRA, UMR 1019, UNH, CRNH Auvergne, F-63000 Clermont-Ferrand

(3) AME2P, Université Blaise Pascal, Clermont-Ferrand

\section{Christelle.Guillet@udamail.fr}

Des rats âgés nourris avec un régime hyperlipidique-hypercalorique (HFD) présentent une résistance de l'anabolisme protéique musculaire, associée à une altération des capacités oxydatives mitochondriales. Comme les apports protéiques influencent l'anabolisme protéique, le but de cette étude était de déterminer si des apports protéiques élevés au sein d'un régime obésogène pourraient prévenir les altérations musculaires induites par le régime HFD. Des rats âgés de 19 mois ont été soumis durant 10 semaines à un régime HFD ou standard (STD) associé à des apports protéiques modérés (12\% de l'apport énergétique total (AET ; STD12, HFD12) ou élevés (25\% de l'AET ; STD25, HFD25).

Au bout de 10 semaines de régime, la variation de masse grasse, évaluée par EchoMRI, est significativement plus élevée dans les groupes HFD (HFD25: +103,5 \pm 33,0g ; HFD12 : $+113,5 \pm 31,6 \mathrm{~g}$ ) que dans les groupes STD (STD25: $+41,2 \pm 20,8 \mathrm{~g} ;$ STD12 : +60,5 \pm 32,4g ; $\mathrm{P}<0,05$, HFD vs STD) quel que soit le niveau d'apport protéique. La variation de masse maigre est significativement plus élevée dans le groupe STD25 $(+34,5 \pm 22,6 \mathrm{~g})$ par rapport aux autres régimes (STD12 : +9,7 $\pm 26,4 \mathrm{~g}$; HFD12 : +21,8 $\pm 24,3 \mathrm{~g}$; HFD25 : +23,4 \pm 14,8g). Les activités enzymatiques mitochondriales, mesurées par spectrophotométrie, ne sont pas modifiées dans le groupe HFD25 alors qu'une diminution significative des activités enzymatiques hydroxyacyl-CoA déshydrogénase (HFD25 : 61,7 \pm 26,1 ; STD25 : 43,3 \pm 14,5 $\mathrm{nmol} / \mathrm{min} / \mathrm{mg}$ prot ; $\mathrm{P}<0,05$ ) et citrate synthase (HFD25 : 606,0 \pm 141,0 ; STD25: 481,2 \pm 54,4 $\mathrm{nmol} / \mathrm{min} / \mathrm{mg}$ prot ; $\mathrm{P}<0,05)$ est observée pour le groupe STD25. Chez le rat âgé, l'effet bénéfique des protéines alimentaires sur l'anabolisme et le métabolisme musculaire n'est pas retrouvé en situation de surnutrition lipidique, suggérant un état de résistance anabolique induit par l'obésité. 


\title{
$\mathrm{CO4}$
}

\section{Des protéines sanguines marqueurs de prédiction du syndrome métabolique? Une étude cas-témoins nichée dans la cohorte Haguenau}

\author{
J Bertrand $^{(1,2)}$, M Pétéra $^{(3)}$, A Fernandes ${ }^{(3)}$, J Matta $^{(4)}$, C Lévy-Marchal ${ }^{(5)}$, \\ S Czernichow ${ }^{(4,6)}$, E Pujos-Guillot ${ }^{(1,2,3)}$, B Comte ${ }^{(1,2)}$
}

(1) INRA, UMR 1019, UNH, équipe Mapping, CRNH Auvergne, F-63000 Clermont-Ferrand,

(2) Clermont Université, Université d'Auvergne, Unité de Nutrition Humaine, BP 10448, F63000 Clermont-Ferrand,

(3) UMR1019, UNH Plateforme d'Exploration du Métabolisme, INRA, Clermont-Ferrand,

(4) UMS011 Cohortes en population, INSERM/Université Versailles St-Quentin, Villejuif,

(5) Institut de Santé Publique, INSERM, Paris,

(6) Département de Nutrition, Hôpital Ambroise Paré, Boulogne,

France

\section{Julien.bertrand@clermont.inra.fr}

La nutrition fœtale est maintenant reconnue comme un facteur de risque pour le développement du syndrome métabolique (SMet) et du diabète de type 2 à l'âge adulte. Cette étude cas-témoins nichée au sein de la cohorte Haguenau a pour objectif d'identifier des biomarqueurs précoces et/ou prédictifs du SMet, associés ou non à l'empreinte fœtale par une approche protéomique ciblée. Elle utilise les données anthropométriques et sociales d'individus nés à la maternité d'Haguenau et identifiés avec ou non un petit poids de naissance ajusté pour l'âge gestationnel (petit poids=SGA, poids normal=AGA). Nous avons sélectionné des sujets SGA, sains à 20 ans ( $T 1, n=56)$, ayant développé (SMet30, $n=27)$ ou non (non SMet30, n=29) un SMet à 30 ans (T2). Une analyse protéomique ciblée a été réalisée sur 56 échantillons biologiques prélevés à $\mathrm{T} 1$ en utilisant des biopuces à protéines. Les résultats ont été analysés pour mettre en évidence des modulations de protéines et identifier des biomarqueurs prédictifs de l'apparition du SMet à T2. Une étape de validation a été effectuée $(n=12)$ pour tester la robustesse du modèle prédictif obtenu. Les résultats ont révélé la variation significative de 47 protéines entre cas et témoins à T1, soit plus de 7 ans avant l'apparition du SMet, et avec un ratio de variation supérieur à 1,5 (n=45) ou inférieur à 0,65 (n=2). Elles sont en majorité impliquées dans la régulation de l'angiogenèse $(n=7)$, de l'inflammation $(n=5)$ ou encore du métabolisme $(n=3)$. D'autres participent à la prolifération cellulaire ou sont impliquées dans le développement fœtal $(n=5)$. Un modèle de régression logistique a permis de retenir 4 protéines avec une capacité prédictive. Ce projet va contribuer à renforcer nos connaissances sur le SMet et l'empreinte fœtale; il va permettre l'identification précoce des sujets à risque pour améliorer leur prise en charge avec une meilleure stratégie préventive. 


\title{
CO5
}

\section{Effet d'un programme d'activité physique intermittent de haute intensité sur la perte de masse grasse abdominale chez la femme DT2 ménopausée}

\author{
F Maillard (doctorante) ${ }^{(1)}$, L Metz $^{(1)}$, S Penando ${ }^{(1)}$, S Rousset $^{(2,3)}$, Y Boirie $^{(2,3,4)}$, \\ M Duclos $^{(2,3,5)}$, N Boisseau ${ }^{(1)}$
}

(1) Université Clermont Auvergne, Université Blaise Pascal, EA 3533, Laboratoire des Adaptations Métaboliques à l'Exercice en Conditions Physiologiques et Pathologiques (AME2P), BP 80026, F-63171, Aubière Cedex, France.

(2) Clermont Université, Université d'Auvergne, Unité de Nutrition Humaine, BP 10448, F-63000

Clermont-Ferrand.

(3) INRA, UMR 1019, UNH, CRNH Auvergne, F-63000 Clermont-Ferrand.

(4) CHU Clermont-Ferrand, Service Nutrition, F-63003 Clermont-Ferrand.

(5) CHU Clermont-Ferrand, Service Médecine du Sport, F-63003 Clermont-Ferrand.

\section{Florie.maillard@gmail.com}

Contexte : A la ménopause, la diminution des taux d'estrogènes favorise un dépôt de masse grasse (MG) abdominal (sous-cutané et viscéral). La MG viscérale est corrélée aux maladies cardio-vasculaires (MCV). Ce risque est accentué chez les sujets présentant un diabète de type 2 (DT2).

Objectif : Comparer deux modalités d'entraînement, continu de moyenne intensité (SSE) vs. intermittent de haute intensité (HIIE), sur la perte de MG abdominale (dont viscérale) chez des femmes DT2 ménopausées.

Matériels et méthode : Seize femmes DT2 ménopausées $\left(69 \pm 1\right.$ ans; IMC : $\left.31 \pm 1 \mathrm{~kg} / \mathrm{m}^{2}\right)$ ont été réparties aléatoirement en deux groupes. Pendant quatre mois, deux fois par semaine, 8 d'entre elles ont réalisé un entraînement SSE (40 min de pédalage à $50 \%$ de la FCmax de réserve), et 8 ont réalisé un entraînement HIIE (8s de sprint suivies de $12 \mathrm{~s}$ de récupération active, pendant $20 \mathrm{~min}$ ). Pré (T0) et post entraînement (T4), la composition corporelle et la MG abdominale totale ont été mesurées par DXA (Dual Energy X-ray Absorptiometry). La MG viscérale a été estimée à partir de la méthode de Martin et Jensen ${ }^{1}$. A T0 et T4, les apports énergétiques et le niveau d'activité physique ont été déterminés (questionnaires et accéléromètrie validée ${ }^{2}$ intégrée sur smartphone).

Résultats : Après 16 semaines d'intervention, sans modification des apports énergétiques et du niveau d'activité physique total, une perte de MG totale et un gain de masse maigre est observé (effet temps, $\mathrm{p}<0.05$ ). La diminution de $M G$ abdominale est supérieure dans le groupe HIIE $(0.32 \% \pm 2.07$ vs $8.32 \% \pm 2.19, p<0.05)$ et la perte de MG viscérale n'est observée que dans le groupe HIIE $(p<0.05)$.

Conclusion : L'entraînement de type HIIE apparait comme un programme alternatif intéressant chez la femme DT2 ménopausée en diminuant significativement la MG abdominale totale et viscérale.

1: Martin ML (1991). J Clin Invest88(2): 609 ; ${ }^{2}$ Guidoux R et al, Journal of Biomedical Informatics 52 (2014) 271278. 


\title{
CO6
}

\section{Contraintes de cisaillement : modulateur des effets vasoprotecteurs des polyphénols?}

\author{
LE Monfoulet $^{(1,2)}$, S Mercier ${ }^{(1,2)}$, D Milenkovic $^{(1,2)}$, C Morand $^{(1,2)}$ \\ (1) Clermont Université, Université d'Auvergne, Unité de Nutrition Humaine, BP 10448, F-63000 \\ Clermont-Ferrand \\ (2) INRA, UMR 1019, Equipe MicroCard, UNH, CRNH Auvergne, F-63000 Clermont-Ferrand
}

\section{laurent-emmanuel.monfoulet@clermont.inra.fr}

De nombreuses études suggèrent que les polyphénols présents dans l'alimentation présentent des propriétés vasoprotectrices en empê-chant les premiers stades de la dysfonction vasculaire et le dévelop-pement de l'athérosclérose. En utilisant des approches de nutrigénomique, nous avons démontré que les polyphénols peuvent protéger l'intégrité de l'endothélium vasculaire en réduisant les interactions entre les monocytes et les cellules endothéliales. Les forces hémodynamiques associées avec le flux sanguin, ou contrainte de cisaillement, constituent un facteur important régulant les interactions inter-cellulaires. Habituellement, les études in vitro visant à déchiffrer l'impact des polyphenols sur les processus moléculaires et cellulaires, sont effectuées dans des conditions statiques. Comme l'exposition chronique des cellules endothéliales à flux laminaire est connue pour affecter les fonctions de la cellule endothéliale, l'objectif de ce travail est d'évaluer l'impact des polyphénols sur la réponse des cellules endothéliales sous contraintes de cisaillement. Ainsi, des cellules endothéliales primaires humaines ont été cultivées sous contrainte de cisaillement afin d'imiter les conditions physiologiques, ou dans des conditions statiques. Les cellules confluentes ont été exposées (3h) à de faibles concentrations de curcumine $(0.5-1 \mu \mathrm{M})$ avant de les stimuler par le TNFalpha (4h). Puis des tests d'adhésion cellulaire ont été réalisés. Les premiers résultats montrent que la pré-exposition des cellules endothéliales à une concentration physiologique de curcumine $(0,5 \mu \mathrm{M})$ sous flux réduit de $40 \%$ l'adhésion de monocytes contre $25 \%$ en conditions statiques. Cette observation suggère que ces contraintes modulent les effets cellulaires de polyphénols. D'autres expérimentations sont en cours pour identifier la réponse nutrigénomique des cellules endothéliales sous contraintes de cisaillement aux polyphénols. 


\title{
$\mathrm{CO}$
}

\section{Implication de la communauté sulfato-réductrice dans la genèse de l'hypersensibilité viscérale chez les sujets atteints du Syndrome de l'Intestin Irritable}

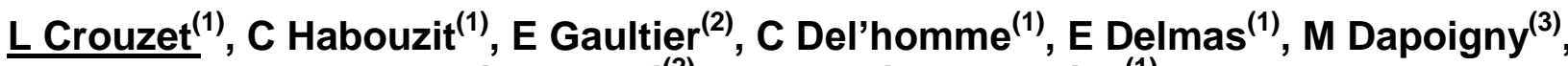 \\ $J_{\text {Fioramonti }}{ }^{(2)}$, A Bernalier-Donadille ${ }^{(1)}$ \\ (1) INRA, UR454, Microbiologie, F-63000 Clermont-Ferrand, France \\ (2) INRA, UMR 1331, Neurogastroentérologie et Nutrition, F-31000 Toulouse, France
}

(3) CHU Estaing, Srevice d'Hépato-Gastroentérologie, F-63000 Clermont-Ferrand, France

Laureen.crouzet@clermont.inra.fr

Le Syndrôme de l'Intestin Irritable est une pathologie digestive fonctionnelle, de faible morbidité mais de prévalence élevée dans la population occidentale, dont l'origine reste mal déterminée et complexe. Une dysbiose du microbiote intestinal et, une hypersensibilité viscérale responsable de douleurs abdominales sont toutefois fréquemment rapportées chez les sujets SII. Cette dysbiose microbienne se caractérise par une population sulfato-réductrice (SRB) accrue de 10 à 100 fois, en particulier chez les sujets SIl-C, par rapport aux sujets sains (Chassard et al, 2012). Cette population est, de plus, plus diversifiée et composée d'espèces différentes chez le sujet SII. Une étude récente (Crouzet et al, 2013) a permis de démontrer que le transfert d'un microbiote fécal de sujet SII à un rat axénique s'accompagnait du transfert de l'hypersensibilité viscérale observée chez le donneur. Ces résultats démontrent l'implication de facteurs d'origine microbienne dans la survenue de la douleur viscérale. L'objectif des travaux qui ont suivi était de déterminer si la communauté SRB, productrice de sulfures, métabolite reconnu aujourd'hui comme gaso-transmetteur, était susceptible d'être à l'origine du phénomène d'hypersensibilté viscérale chez le sujet SIl. Une première série d'expérimentation a été réalisée chez le rat né axénique puis transplanté avec le microbiote fécal de sujet sain. Ces animaux ont ensuite reçu, par gavage oro-gastrique pendant 15 jours, une dose journalière d'une souche SRB isolée au laboratoire à partir des selles d'un sujet SII. Alors que les rats à microbiote de sujet sain étaient normo-sensibles, ceux ayant reçus la souche SRB présentaient une hypersensibilité viscérale, semblable à celle mesurée chez les rats à microbiote fécal de sujet SII, et une concentration caecale en sulfures élevée. Ces résultats montrent ainsi qu'une augmentation du niveau de population et de l'activité SRB au sein du microbiote intestinal s'accompagne de l'apparition d'une hypersensibilité viscérale. Une deuxième série d'expérimentations réalisées chez le rat conventionnel recevant (ou non) une dose journalière d'une souche SRB est actuellement en cours afin de démontrer l'effet de cette communauté SRB chez un modèle animal non re-conventionnalisé (implanté naturellement) et normo-sensible. 


\title{
$\mathrm{CO8}$
}

\section{Les bactéries du microbiote intestinal : de nouveaux acteurs impliqués dans le cancer colorectal}

\author{
G Dalmasso ${ }^{(1)}, \mathbf{J}$ Delmas ${ }^{(1,2)}$, M Bonnet $^{(1)}, \mathbf{N}$ Barnich ${ }^{(1)}$, R Bonnet ${ }^{(1,2)}$ \\ (1) Laboratoire M2iSH, Inserm UMR 1071/Uda, Usc INRA 2018, Clermont-Ferrand \\ (2) Laboratoire de bactériologie, CHU Gabriel Montpied, Clermont-Ferrand \\ Guillaume.dalmasso@udamail.fr
}

Le cancer colorectal (CCR) est le troisième cancer en terme de fréquence. Seulement $10 \%$ des cas sont d'origine héréditaire et de nombreux facteurs de risques ont été identifiés. Parmi eux, le microbiote intestinal, c'est-à-dire l'ensemble des microorganismes hébergés dans le tractus digestif, est suspecté de jouer un rôle central dans le développement du CCR. A l'heure actuelle, les bactéries du microbiote intestinal font l'objet de nombreuses recherches afin d'identifier les souches potentiellement impliquées dans le CCR. II a notamment été montré que les patients souffrant d'un CCR présentent une dysbiose, c'est-à-dire un déséquilibre dans la composition du microbiote bactérien intestinal. Certaines espèces bactériennes sont fortement suspectées d'être impliquées dans le CCR car, en plus d'être surreprésentées au niveau du site tumoral, elles peuvent produire de nombreuses toxines capables de modifier fortement la physiologie des cellules épithéliales intestinales en activant par exemple le cycle cellulaire ou en cassant l'ADN. Les Escherichia coli sont parmi les bactéries les plus étudiées. En effet, elles colonisent fortement les tumeurs colorectales et plus de $50 \%$ d'entre elles produisent une génotoxine appelée colibactine. Cette dernière provoque une instabilité chromosomique ainsi qu'une augmentation du nombre de tumeurs dans un modèle murin prédisposé au CCR. Récemment il a été montré que le ciblage des gènes permettant la synthèse de la colibactine prévient son effet délétère. Ainsi les bactéries du microbiote intestinal pourraient devenir dans les années qui viennent des marqueurs de prédisposition de CCR et pourraient également être la cible de médicaments afin de prévenir/d'atténuer le développement du CCR. 


\title{
C09
}

\section{Isolement de Methanomethylophilus alvus gen. nov., sp. nov., archée méthanogène métabolisant le précurseur de l'agent plasmatique proathérogène TMAO}

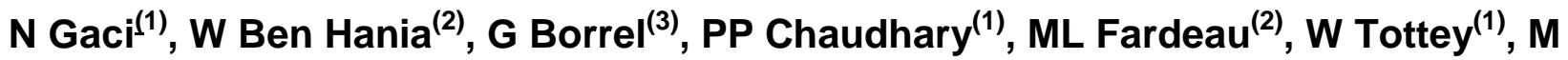 \\ Alric $^{(1)}$, PW O'Toole ${ }^{(3)}$, B Ollivier ${ }^{(2)}$, JF Brugère ${ }^{(1)}$ \\ (1) EA 4678 CIDAM, Université d'Auvergne, Clermont-Ferrand, France \\ (2) MEB, Institut Méditerranéen d'Océanologie, Aix-Marseille Université, Luminy, France \\ (3) Alimentary Pharmabiotic Centre, University College Cork, Cork, Ireland

\section{jf.brugere@udamail.fr}

La triméthylamine (TMA) intestinale est issue du métabolisme de divers nutriments (phosphatidylcholine et choline, TMAO, L-carnitine,...) par le microbiote intestinal. Elle forme l'unique précurseur du TMAO, métabolite plasmatique proathérogène, ce qui en fait une cible privilégiée de prévention de l'athérosclérose.

Nous rapportons le premier isolement d'une archée méthanogène du cluster « digestif » de l'ordre des Methanomassiliicoccales à partir d'un microbiote fécal humain : 'Methanomethylophilus alvus' gen. nov, sp. nov, est une espèce commune du microbiote intestinal de la personne âgée en bonne santé et utilisant la TMA comme substrat de méthanogenèse. La création de la famille 'Methanomethylophilaceae' fam. nov. est proposée en conséquence de la faible identité de séquence de l'ARNr 16S avec l'autre espèce isolée de cet ordre, Methanomassiliicoccus luminyensis (Dridi et al., 2012), appartenant au cluster mixte « digestif/environnemental ».

Les données génomiques de ' $M$. alvus' montrent diverses signatures d'adaptation à l'environnement digestif, la capacité de synthèse et d'encodage de l'acide aminé rare pyrrolysine (Pyl), ainsi qu'une méthanogenèse obligatoirement réalisée à partir de composés méthylés tels que le méthanol ou les méthylamines. Cette méthanogenèse est avérée en culture en présence d'H2, gaz abondant au niveau intestinal, pour la TMA. Le méthane étant considéré comme inerte au niveau physiologique chez l'homme, et sur la base de cette propriété de conversion de la TMA, cet isolement ouvre la voie à son évaluation comme archaebiotique, agent probiotique archéen préventif de pathologies humaines telles que la triméthylaminurie ou l'athérosclérose. 


\title{
C010
}

\section{Identification de perturbateurs chimiques des LIVER X RECEPTORS impliqués dans le cancer de la prostate}

\author{
$\underline{\text { A Fouache }^{(1)}}$, M Poirot $^{(2)}$, S Baron ${ }^{(1)}$, DH Volle $^{(1)}$, A Trousson $^{(1)}$, JM Lobaccaro(1) \\ (1) Laboratoire GReD, UMR CNRS6293-INSERMU1103 - Université Clermont Auvergne; 63178 \\ Aubière Cedex \\ (2) UMR INSERM1037 - Centre de Recherche en Cancérologie de Toulouse, 31052 Toulouse, France

\section{allan.fouache@etudiant.univ-bpclermont.fr}

Ces dernières années ont été marquées par l'augmentation de l'incidence des maladies métaboliques et des cancers, notamment de la prostate. Par une exposition continue à faible dose, des molécules présentes dans notre environnement comme les perturbateurs chimiques environnementaux pourraient être impliquées dans ce phénomène. Les récepteurs nucléaires Liver $X$ Receptors (LXRs) ont un rôle protecteur envers la carcinogenèse prostatique épithéliale. Nous nous sommes demandé si certains perturbateurs chimiques alimentaires pouvaient, en partie, altérer les voies de signalisation régulées par les LXRs.

A partir d'une analyse in silico, nous avons sélectionné le BPA et le chlordécone, considérés comme des perturbateurs chimiques environnementaux. Ils ont été testés en culture cellulaire avec le système UAS-GAL4 pour évaluer leurs effets sur le domaine de liaison du ligand des LXRs. Nous avons aussi évalué l'effet du BPA et du chlordécone sur leur capacité à interférer avec l'activité de l'hétérodimère LXR-RXR et sur l'accumulation des transcrits cibles de LXRs. Le BPA et le chlordécone ont un effet antagoniste sur les LXRs. Les $I_{50}$ ont été calculées et sont de 3,34 $\mu \mathrm{M}$ pour le chlordécone et 0,75 $\mu \mathrm{M}$ pour le BPA sur LXRa, et de 1,06 $\mu \mathrm{M}$ pour le chlordécone et 2,12 $\mu \mathrm{M}$ pour le BPA sur $L X R \beta$. Ces $I_{50}$ sont en accord avec les concentrations circulantes chez l'Homme. Ces deux molécules diminuent également l'activité du dimère LXR-RXR et l'accumulation des transcrits cibles des LXRs.

Nous montrons que BPA et chlordécone, deux molécules impliquées dans le risque de développement d'un cancer de la prostate, sont des perturbateurs chimiques environnementaux des récepteurs LXRs. 


\title{
C011
}

\section{Influence de la leptine, de l'IL6 et de traitements anticancéreux sur la prolifération de cellules souches cancéreuses}

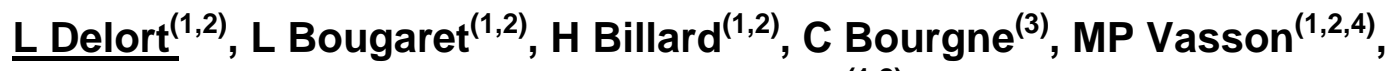 \\ F Caldefie-Chézet ${ }^{(1,2)}$ \\ (1) Clermont Université, Université d'Auvergne, Unité de Nutrition Humaine, Equipe ECREIN, UFR \\ Pharmacie BP 10448, F-63000 CLERMONT-FERRAND \\ (2) INRA, UMR 1019, UNH, CRNH Auvergne, F-63000 CLERMONT-FERRAND \\ (3) Service d'Hématologie Biologique, CHU Estaing, Clermont Ferrand \\ (4) Cancéropôle Lyon Auvergne Rhône-Alpes (CLARA), Lyon \\ laetitia.delort@udamail.fr
}

Bien que les traitements anticancéreux soient de plus en plus performants et ciblés chez les femmes porteuses de tumeur mammaire, le risque de récidives et d'échappement tumoral à la thérapie n'est pas nul. Récemment, l'hypothèse d'une implication des cellules souches cancéreuses (CSC) dans la résistance thérapeutique a été émise. Par ailleurs, l'obésité et certaines sécrétions adipocytaires (i.e. adipokines) telles que la leptine et I'IL-6, dont les concentrations sériques sont augmentées en cas d'obésité, sont aussi associées à un risque accru de développement de cancer du sein et de récidives. Aussi, l'objectif de cette étude a consisté à mettre au point une technique d'isolement des CSC afin d'évaluer leur comportement en présence de traitements anti-cancéreux et d'adipokines.

Pour cela, des CSC ont tout d'abord été isolées par cytométrie en flux (FACS) à partir de cellules cancéreuses mammaires MCF-7 cultivées ou non sous la forme de mammosphères, puis mises en présence de différents traitements anti-cancéreux d'hormonothérapie (tamoxifène, 4-OH-tamoxifène, fulvestrant), de chimiothérapie (doxorubicine) ainsi que de deux adipokines (leptine, IL6) pour évaluer leur prolifération.

La proportion de CSC MCF-7 isolées (test d'exclusion du Hoechst, CD24 $4^{\mathrm{low}} / \mathrm{CD} 44^{+}$et ALDH1 ${ }^{+}$) est augmentée lorsque celles-ci sont cultivées sous forme de mammosphères. De plus, les CSC isolées voient leur prolifération augmentée en présence de traitements anticancéreux mais également en présence de leptine et d'IL-6.

Ainsi, ces travaux préliminaires suggèrent que les thérapies anti-tumorales et les adipokines pourraient favoriser la prolifération des CSC et, de ce fait, jouer un rôle majeur dans le risque de récidives et la moindre efficacité des traitements. Ceci pourrait être à considérer lors de la prise en charge des patientes cancéreuses en situation de surpoids. 


\title{
C012
}

\section{Modifications des histones H3 dans les différents sous-types moléculaires du cancer du sein}

\author{
$\underline{\text { G Judes }}^{(1,2)}$, A Dagdemir ${ }^{(1,2)}, \mathbf{S}$ Karsli-Ceppioglu ${ }^{(1,2)}$, A Lebert $^{(3)}, \mathbf{M ~ N g o l l o ~}^{(1,2)}$, \\ YJ Bignon ${ }^{(1,2)}$, F Penault-Llorca ${ }^{(2,4)}$, D Bernard-Gallon ${ }^{(1,2)}$ \\ (1) Département d'Oncogénétique, Centre Jean Perrin, CBRV, 28 place Henri Dunant, 63001, \\ Clermont-Ferrand, France \\ (2) EA 4677 "ERTICA", Université d'Auvergne, 63011, Clermont-Ferrand, France \\ (3) Université Blaise Pascal, Institut Pascal, UMR 6602 CNRS/UBP, 63177, Aubière, France \\ (4) Laboratoire de Pathologie, Centre Jean Perrin, 63011, Clermont-Ferrand, France \\ judes.gaelle@wanadoo.fr
}

Le cancer du sein est une maladie hétérogène qui présente de multiples variations au niveau clinique, morphologique et moléculaire. Elle implique aussi des altérations génétiques et épigénétiques. Des avancées dans l'analyse moléculaire ont permis de déterminer différentes classifications du cancer du sein. De ce fait, nous avons étudié le profil épigénétique de l'histone H3 selon les différents sous-types moléculaires de la classification de St Gallen. Une cohorte de 192 tumeurs du sein et 192 tissus normaux associés, avec des paramètres clinicopathologiques connus a été classée selon les 5 sous-types moléculaires de St Gallen (luminal A, luminal B HER2-, luminal B HER2+, HER2+ and basal-like). Dans cette population, des modifications des histones H3 (H3K27me3, H3K9ac et H3K4ac) ont été étudiées par immunoprécipitation de la chromatine suivie d'une Q-PCR sur le promoteur de certains gènes impliqués dans les voies de signalisation des cancers du sein. Une analyse comparative (ANOVA) a identifié des signatures spécifiques de H3 en fonction du gène et du type de cancer du sein; 3 groupes de gènes ont été mis en évidence: les récepteurs hormonaux (ERS1, ERS2, PGR), les gènes codant pour des enzymes modifiant les histones (EZH2, P300, SRC3) et le gène suppresseur de tumeur BRCA1. De plus, un profil épigénétique similaire a été retrouvé au sein des cancers à haut risque (luminal B (HER2+), HER2+ et basal-like) et ce profil apparaît différent dans les cancers à bas risque (luminal $A$ et luminal $B$ (HER2-)). Deux modèles analytiques (analyse comparative discriminante et arbre de décision) nous ont permis d'identifier les modifications épigénétiques de l'histone H3 sur les gènes appartenant à chaque sous-type. 
POSTERS 


\title{
P1
}

\section{Identification de bio-marqueurs prédictifs et précoces de l'ostéoporose : approche préclinique}

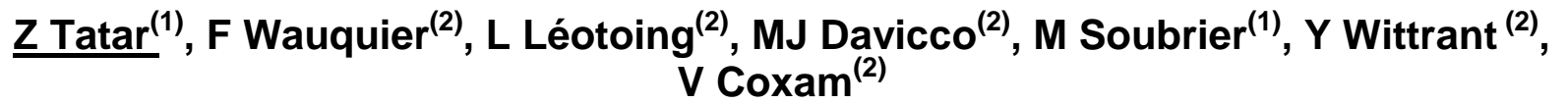 \\ (1) Service de Rhumatologie, CHU Gabriel Montpied, Clermont Ferrand, France \\ (2) UNH, UMR 1019, INRA, Clermont-Ferrand, 2UNH, INRA, Saint Genès Champanelle, Clermont- \\ Ferrand, France

\section{ztatar@chu-clermontferrand.fr}

L'ostéoporose est un problème majeur de santé publique car elle est associée à une augmentation de la morbi-mortalité générant une charge financière importante. L'objectif de cette étude préclinique a été d'identifier in vivo de biomarqueurs robustes, précoces et prédictifs de dérives des processus de calcification dans l'ostéoporose.

Des prélèvements sanguins (afin d'isoler par tri magnétique les précurseurs d'ostéoclastes, les monocytes $L y-6 C$ ) et de la moelle osseuse ont été effectués chez des souris ovariectomisées (modèle classique d'étude de l'ostéoporose) et pseudo-opérées à 3, 17 et 39 jours après la chirurgie. Une analyse transcriptomique, par TLDA et real-time $P C R$, a été réalisée, en vue d'une identification des biomarqueurs pertinents de l'ostéoporose.

Les résultats ont mis en évidence une sous-expression des récepteurs aux acides gras (GPR40, GPR120, TLR2, TLR4) chez les souris ovariectomisées, dès les stades très précoces et donc pré-cliniques de l'ostéoporose (J3). Ces marqueurs sont associés à l'initiation du processus de perte osseuse et ils pourraient également servir en tant qu'indicateurs précoces du déclenchement du mécanisme pathologique de l'ostéoporose.

D'autres travaux complémentaires devraient maintenant être menés chez la souris, afin d'éclaircir toute la cascade de signalisation impliquée, mais également chez l'homme en vue de validation de ces composants en tant que de « nouveaux » biomarqueurs de l'ostéoporose. 


\title{
Effect of anthocyanins and their microbiota metabolites on monocyte adhesion to endothelial cells at physiologically relevant concentrations
}

\author{
I Krga ${ }^{(1,2,3)}$, S Mercier ${ }^{(1,2)}$, L-E Monfoulet ${ }^{(1,2)}$, C Morand $^{(1,2)}$, A Konic-Ristic ${ }^{(3)}$, \\ D Milenkovic ${ }^{(1,2)}$
}

1) Clermont Université, Université d'Auvergne, Unité de Nutrition Humaine, BP 10448, F-63000

Clermont-Ferrand

(2) INRA, UMR 1019, UNH, CRNH Auvergne, F-63000 Clermont-Ferrand

(3) Centre of Research Excellence in Nutrition and Metabolism, Institute for Medical Research,

University of Belgrade, Serbia

\section{Dragan.Milenkovic@clermont.inra.fr}

Epidemiological studies suggest a protective role of dietary anthocyanins, micronutrients present mainly in berries, against cardiovascular diseases. Clinical and pre-clinical studies showed effects on improvements in endothelial function, modulation of inflammation or decreased atherosclerosis development. However, the underlying cellular and molecular mechanisms still remain unknown. The aim of the present study was to investigate the effect of anthocyanins and their gut metabolites identified in plasma on monocyte adhesion to TNFastimulated endothelial cells, the initial step of atherosclerosis development.

Human umbilical vein endothelial cells (HUVECs) were exposed to cyanidin-3-O-glucoside, cyanidin-3-O-galactoside, cyanidin-3-O-arabinoside, delphinidin-3-O-glucoside, peonidin-3-Oglucoside and 4-hydroxybenzaldehyde for 3 hours and to protocatechuic, ferulic, hippuric and vanillic acid for $18 \mathrm{~h}$ at physiologically-relevant concentrations, all at $0.1 \mu \mathrm{M}, 0.2 \mu \mathrm{M}, 0.5 \mu \mathrm{M}$, $1 \mu \mathrm{M}$ and $2 \mu \mathrm{M}$. Subsequently, HUVECs were stimulated with TNFa $(1 \mathrm{ng} / \mathrm{ml})$ for 4 hours followed by 15 minutes incubation with monocytes. Monocytes adhesion to HUVECs was determined using the flow cytometry.

This study showed that exposure of HUVECs to cyanidin-3-O-galactoside, cyanidin-3-Oarabinoside, delphinidin-3-O-glucoside and peonidin-3-O-glucoside significantly attenuated monocyte adhesion at $0.1 \mu \mathrm{M}$ by $27.4 \%$ in average. Ferulic acid decreased adhesion at $1 \mu \mathrm{M}$ and $2 \mu \mathrm{M}$ by $28.5 \%$, hippuric at $2 \mu \mathrm{M}$ by $18.1 \%$ and protocatechuic by $36.5 \%$ at all concentrations. Exposure of HUVECs to mixture of compounds used in 3-hour exposure period, resulted in adhesion decrease by $28.3 \%$.

In conclusion, this study showed the biological potency of plasma anthocyanins and their gut metabolites to modulate the adhesion of monocyte to endothelial cells at physiologicallyrelevant concentrations. The further investigation using nutrigenomics approaches is needed to decipher underlying molecular mechanisms of action. 


\title{
Comparative study of EHEC survival and virulence under adult and infant simulated digestive conditions
}

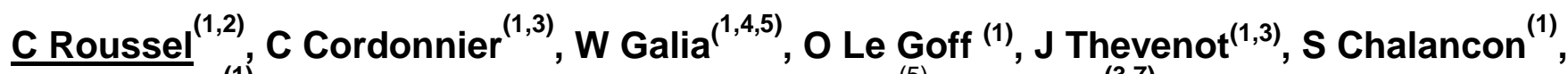 \\ M Alric $^{(1)}$, D Thevenot-Sergentet ${ }^{(4,6)}, F_{\text {Leriche }}^{(5)}, V_{\text {Livrelli }}^{(3,7)}$, T Van de Wiele $^{(2)}$, \\ S Blanquet-Diot ${ }^{(1)}$
}

(1) Clermont Université, Université d'Auvergne, Centre de Recherche en Nutrition Humaine Auvergne,

EA 4678 CIDAM, Conception Ingénierie et Développement de l'Aliment et du Médicament, ClermontFerrand, France

(2) LabMet, Laboratory of Microbial Ecology and Technology, Ghent University, Ghent, Belgium

(3) Clermont Université, Université d'Auvergne, Centre de Recherche en Nutrition Humaine Auvergne, M2iSH, Microbes, Intestin, Inflammation et Susceptibilité de l'Hôte UMR INSERM / Université d'Auvergne U1071 USC-INRA 2018, Clermont-Ferrand, France

(4) Université de Lyon, Research Group on Bacterial Opportunistic Pathogens and Environment, UMR 5557 Ecologie Microbienne, CNRS, VetAgro Sup and Université Lyon1, Lyon, France

(5) Université de Clermont-Ferrand, VetAgro Sup, Campus Agronomique de Lempdes, Unité CALYTISS, Lempdes, France

(6) Université de Lyon, VetAgro Sup, Campus Vétérinaire de Lyon, Laboratoire d'Etude des Microorganismes Alimentaires Pathogènes, French National Reference Laboratory for Escherichia coli including Shiga Toxin-Producing E. coli, Marcy l'Etoile, France

(7) $\mathrm{CHU}$ Clermont-Ferrand, Service de Bactériologie, Clermont-Ferrand, France

stephanie.blanquet@udamail.fr

\begin{abstract}
Introduction
Enterohemorrhagic Escherichia coli (EHEC) are major food and waterborne pathogens that constitute a serious public health threat, mainly in young infants where they cause the life-threatening complication hemolytic uremic syndrome. E. coli $\mathrm{O} 157: \mathrm{H} 7$ is responsible for the most severe outbreaks worldwide. The main virulence determinant of EHEC is the production of Shiga toxin. Survival and virulence of EHEC strains in the human gastrointestinal tract are key factors in bacterial pathogenesis but remain unclear, particularly in infant, owing to a lack of relevant model.

Method

The aim of the present study was to use a new infant protocol in the dynamic gastric and small intestinal TIM model for a comparative study of E. coli O157:H7 survival and virulence under adult and infant conditions. The reference strain E. coli O157:H7 EDL 933 was administered into the TIM within a glass of water. Culturable and viable cells were followed by plate count and flow cytometry, respectively. The expression of the main virulence genes was studied by RT-qPCR and the production of Shiga toxins was measured by ELISA.

Results and discussion

For the first time, a higher amount of cells, what is more in a better physiological state, was found in the ileal effluents of infant compared to adult. stx genes were over-expressed in infant conditions compared to the adult ones, in correlation with a higher amount of Shiga toxins produced. Our results show that differences in digestive physicochemical parameters of the upper gastrointestinal tract may partially explain why infants are more susceptible to EHEC infection than adults.

Implication

Such data are essential for a full understanding of EHEC pathogenesis and would help in designing novel therapeutic approaches, particularly in the infant high-risk population.
\end{abstract}




\title{
Régulation de la marque H3K27me3 par la déméthylase d'histone JMJD3 et la méthyltransférase EZH2 dans les cancers de la prostate
}

\author{
M Daures $^{(1,2)}$, M Ngollo $^{(1,2)}$, G Judes $^{(1,2)}, \mathrm{K}_{\text {Rifai }}{ }^{(1,2)}$, JL Kemeny $^{(3)}$, F Penault-Llorca $^{(1,2)}$, \\ YJ Bignon ${ }^{(1,2)}$, L Guy ${ }^{(2,4)}, D$ Bernard-Gallon ${ }^{(1,2)}$ \\ (1) Département d'Oncogénétique, Centre Jean Perrin, CBRV, 28 place Henri Dunant, BP 38, 63001 \\ Clermont-Ferrand, France \\ (2) EA 4677 “ERTICA", Université d'Auvergne, 28 place Henri Dunant, BP 38, 63001 Clermont-Ferrand \\ France \\ (3) Département de Pathologie, CHU Gabriel-Montpied, 58 rue Montalembert, 63000 Clermont-Ferrand \\ cedex 1, France \\ (4) Département d'Urologie, Gabriel Montpied Hospital, 58 rue Montalembert, 63001 Clermont-Ferrand, \\ France \\ marine.daures63@gmail.com
}

En France comme dans la majorité des pays développés, le cancer de la prostate est le plus fréquent chez l'homme. Il a été clairement établi que les altérations génétiques et épigénétiques sont des événements communs dans les cancers de la prostate, se traduisant par l'expression aberrante de gène critique. La méthylation des histones participe à la régulation de l'expression des gènes dans la cellule. La triméthylation de la lysine 27 de l'histone H3 (H3K27me3) est une marque associée à la répression génique et se trouve dérégulée dans les cancers de la prostate. Par ailleurs, les niveaux de H3K27me3 sont déterminés par l'équilibre entre les activités de la méthyltransférase d'histone $\mathrm{EZH} 2$ et de la déméthylase d'histone JMJD3. II a été démontré que ces deux protéines sont surexprimées dans les cancers de la prostate. Sachant que JMJD3 et EZH2 ont des effets opposés, le but de cette étude a été de déterminer leurs niveaux dans les cancers de la prostate ainsi que leurs rôles sur le développement et la progression tumorale. Pour cela, des études transcriptionelles par

RT-qPCR et protéiques par Western-Blot sur des lignées continues de cancer de prostate (PC-3 et LNCaP) et saine (PWR-1E) et sur des biopsies de prostate humaine ont été réalisées afin de déterminer les niveaux de JMJD3 et d'EZH2. De plus, une immunoprécipitation de la chromatine suivie d'une qPCR (ChIP-qPCR) visant les gènes cibles ERa, RARß2 et RGMA modulés par H3K27me3 a été réalisée afin de déterminer des cibles de la déméthylase JMJD3 et de la méthyltransférase EZH2.

Les résultats montrent une augmentation significative de JMJD3 dans la lignée tumorale LNCaP positive aux récepteurs aux androgènes suggérant un lien entre la voie métabolique des androgènes et la déméthylase. EZH2 est aussi augmentée dans les différentes lignées tumorales. De plus, cette étude a mis en évidence trois gènes cibles communs : ERa, RARß2 et RGMA. Par ailleurs, ces travaux montrent le rôle clé de JMJD3 dans le développement métastasique. RARß2 semble être aussi une cible privilégiée de la déméthylase ce qui en ferait une potentielle cible thérapeutique. 


\title{
Etude de l'impact de composés circulants issus de la consommation d'huile d'olive, vierge ou raffinée, enrichie ou non en Vitamine D, sur la biologie des cellules osseuses
}

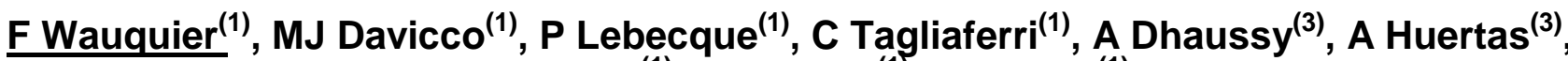 \\ $S$ Walrand ${ }^{(1)}, Y$ Wittrant $^{(1)}, V$ Coxam $^{(1)}$ \\ (1) Clermont Université, Université d'Auvergne, Unité de Nutrition Humaine, BP 10448, F-63000 \\ Clermont-Ferrand \\ (2) INRA, UMR 1019, UNH, CRNH Auvergne, F-63000 Clermont-Ferrand \\ (3) Lesieur, 29 quai Aulagnier, 92665 Asnières-sur-Seine, France
}

\section{Fabien.Wauquier@clermont.inra.fr}

Au sein des pays industrialisés, la prévalence des maladies chroniques liées à l'âge est en constante augmentation. Parmi ces pathologies, les atteintes de l'appareil locomoteur telles que l'ostéoporose, sont particulièrement handicapantes. Ces trente dernières années, d'importantes avancées scientifiques dans le domaine de la nutrition sont venues appuyées l'idée selon laquelle le régime alimentaire a un rôle important à jouer dans le maintien du capital osseux.

Sur la base de la littérature et de données préliminaires, nous avons émis l'hypothèse selon laquelle les propriétés anti-oxydantes et anti-inflammatoires des micronutriments de l'huile d'olive (comme les polyphénols), en association avec la vitamine $D$, pourraient avoir un effet protecteur sur l'évolution du tissu osseux avec l'âge.

Un effet protecteur de l'huile d'olive vierge (riche en polyphénols), enrichie en vitamine $D$, a pu être mis en évidence au niveau de la densité minérale osseuse, dans un modèle murin d'ostéoporose. Cet effet n'est pas retrouvé lorsque les composés sont consommés seuls suggérant une action synergique de ces composés. Cela est confirmé par l'analyse ex vivo d'échantillons de sérums issus de souris ayant été gavées avec de l'huile d'olive vierge et de la vitamine $D$, qui favorisent la différentiation de la lignée ostéoblastique MC3T3-E1 et limitent celle des précurseurs ostéoclastiques Raw 264.7.

Ce travail a permis de mettre en valeur le potentiel, pour la santé osseuse, de l'action combinée des polyphénols d'huile d'olive et de la vitamine $D$. 


\title{
P6
}

\section{Bioactive oxylipins derived from DHA: neuroprostanes contribute to the anti-inflammatory action of DHA through the inhibition of NFKB and independently to PPAR $\gamma$}

\author{
C Gladine $^{(1,2)}$, L Joumard-Cubizolles ${ }^{(1,2)}, G_{\text {Chinetti }}^{(3)}$, D Bayle $^{(1,2)}$, C Copin $^{(3)}$, \\ N Hennuyer ${ }^{(3)}$, B Staels ${ }^{(3)}$, G Zanoni ${ }^{(4)}$, A Porta $^{(4)}$, JM Galano ${ }^{(5)}$, C Oger $^{(5)}$, A Mazur $^{(1,2)}$, \\ T Durand ${ }^{(5)}$
}

(1) Clermont-Ferrand INRA, UMR 1019, UNH, CRNH Auvergne, F-63000 Clermont-Ferrand (2) Clermont Université, Université d'Auvergne, Unité de Nutrition Humaine, BP 10448, F-63000

(3) UMR1011 INSERM/Université de Lille 2/Institut Pasteur, Lille, France

(4) Université de Pavie, Pavie, Italie

(5) IBMM, UMR 5247 CNRS/UM I/UM II, Montpellier, France

\section{cecile.gladine@clermont.inra.fr}

Oxylipins is a generic term representing the whole oxygenated metabolites produced through the enzymatic and non-enzymatic oxygenation of PUFAs. Oxylipins generated by free radical mediated peroxidation such as iso- and neuroprostanes have been restricted for a long time to oxidative stress biomarkers but several lines of evidence now suggest interesting signalling actions. In the present study, we aimed at investigating the anti-inflammatory properties of Neuroprostanes, a specific class of non-enzymatic oxylipins derived from DHA. Human peripheral blood mononuclear cells were isolated from healthy donors by Ficoll density gradient centrifugation. Monocytes were differentiated into resting macrophages (RM) for 6 days $\left(37^{\circ} \mathrm{C}, 5 \% \mathrm{CO} 2\right)$ which were then exposed to 2 different types of NeuroPs (i.e. $14-\mathrm{A}_{4}-$ NeuroP and $4-\mathrm{F}_{4 \mathrm{t}}-\mathrm{NeuroP}, 10 \mu \mathrm{M}$ ) or vehicle (ethanol $0.15 \%$ ) during $30 \mathrm{~min}$. Inflammatory response was induced by LPS $(100 \mathrm{ng} / \mathrm{mL})$ for $6 \mathrm{hrs}$. When RM macrophage were preexposed with 14- $\mathrm{A}_{4}-\mathrm{NeuroP}$ and $4-\mathrm{F}_{4 \mathrm{t}}-\mathrm{NeuroP}$, significant decrease of mRNA abundance for IL-6 (-49\% and $-26 \%$ respectively) and MCP-1 (-55\% and $-24 \%$ respectively) were measured after LPS activation. Secretion of TNFa and MCP-1 was also reduced when RM were preexposed to $14-\mathrm{A}_{4}-$ NeuroP $(-10 \%$, ns and $-34 \%, \mathrm{p}<0.05)$ and $4-\mathrm{F}_{4 \mathrm{t}}-$ NeuroP $(-12 \%, \mathrm{p}<0.01$ and $25 \%, n s)$. Preliminary results regarding the expression and phosphorylation of $I_{\kappa} \mathrm{B} \alpha$ show a reduced level of phosphorylated $\mathrm{I} \kappa \mathrm{B} \alpha$ with $4-\mathrm{F}_{4 \mathrm{t}}-\mathrm{NeuroP}$ suggesting the inhibition of $\mathrm{NF} \kappa \mathrm{B}$ pathway. Finally, co-transfection of luciferase reporter vector with hPPAR $\gamma$ expression vector performed on Cos-7 cells showed a weak interaction of NeuroPs with PPAR indicating that NeuroPs probably act independently of PPAR $\gamma$.

In conclusion, these results suggest that the anti-inflammatory properties of DHA could be mediated, at least in part, by NeuroPs which corroborates the role of free-radical mediated reactions in cell signaling. 


\title{
EHEC interactions with Peyers patches and antagonistic effect of the probiotic yeast Saccharomyces cerevisiae
}

\author{
C Cordonnier ${ }^{(1,2)}$, L Etienne-Mesmin ${ }^{(1,2)}$, J Thévenot $^{(1,2)}$, H Nguyen $^{(1)}, \mathbf{N}$ Barnich $^{(1)}$, \\ S Blanquet-Diot ${ }^{(2)}$, V Livrelli ${ }^{(1,3)}$
}

(1) Clermont Université, Université d'Auvergne, Centre de Recherche en Nutrition Humaine Auvergne, M2iSH, Microbes, Intestin, Inflammation et Susceptibilité de l'Hôte UMR INSERM / Université d'Auvergne U1071 USC-INRA 2018, Clermont-Ferrand, France

(2) Clermont Université, Université d'Auvergne, Centre de Recherche en Nutrition Humaine Auvergne, EA 4678 CIDAM, Conception Ingénierie et Développement de l'Aliment et du Médicament, Clermont-

Ferrand, France

(3) CHU Clermont-Ferrand, Service de Bactériologie, Clermont-Ferrand, France

Charlotte.cordonnier@udamail.fr

Enterohemorrhagic Escherichia coli (EHEC) are important food-borne pathogens responsible for human diseases ranging from uncomplicated diarrhoea to life-threatening complications such as hemolytic-uremic syndrome. Among EHEC strains, O157:H7 is the main serotype involved in sporadic cases and outbreaks. Shiga toxin (Stx) is the main virulence factor, but adherence and colonization of the intestinal epithelium are also essential components of EHEC pathogenesis. Recent studies have shown that EHEC preferentially interact with the Follicule-Associated Epithelium (FAE) of Peyer's patches (PPs) of the distal ileum in humans, and translocate across the intestinal epithelium via $M$ cells. As no specific treatment is available for EHEC infections and as antibiotic therapy has worsened clinical outcomes, alternative strategies using probiotics are considered. In the present study, complementary in vitro and in vivo approaches have been used to assess the effect of the probiotic yeast strain Saccharomyces cerevisiae CNCM I-3856 on EHEC interactions with the intestinal epithelium. In vitro, the antagonistic effect of the probiotic on 0157:H7 EDL933 interactions with M-like cells was investigated using an original model of specialized $\mathrm{M}$ cells. In vivo, mice were given the probiotic for 7 days before ileal loops assays were conducted with 0157:H7 EDL 933. S. cerevisiae significantly reduced the translocation of $\mathrm{E}$. coli $\mathrm{O} 157: \mathrm{H} 7$ through $\mathrm{M}$ cells monolayers and inhibited in vivo interactions of the pathogen with PPs. Besides, the probiotic exerted a trophic effect on the intestinal mucosa. Following EHEC infection in murine ileal loops, bloodshot PPs were macroscopically observed. Pre-treatment with the probiotic yeast significantly reduced the number of hemorrhagic PPs in murine ileal loops. Together, our data indicate that tropism of EHEC to PPs can be limited by the probiotic S. cerevisiae. 


\title{
P8
}

\section{La propolis régule la survie des cellules LNCaP en culture}

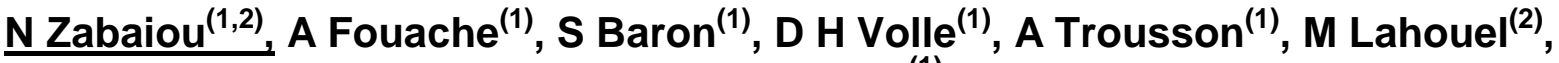 \\ JM Lobaccaro ${ }^{(1)}$ \\ (1) Laboratoire GReD, UMR CNRS6293-INSERMU1103 - Université Clermont Auvergne; 63178 \\ Aubière Cedex \\ (2) Laboratoire de Toxicologie Moléculaire, Département de Biologie Moléculaire et Cellulaire, \\ Université de Jijel, Algérie
}

\section{Nada-biologie@hotmail.com}

Le cancer de la prostate est le cancer le plus diagnostiqué chez l'homme à travers le monde et constitue la deuxième cause de décès après celui du poumon. Le traitement de ce cancer est en amélioration permanente. Si un traitement curatif est possible en cas de cancer localisé, le cancer avancé développant des métastases est inaccessible à un tel traitement. La majeure partie des patients répond initialement au blocage des androgènes. Au-delà des effets indésirables, une résistance aux traitements antiandrogènes se met en place inexorablement. II est donc indispensable de développer de nouvelles approches thérapeutiques à partir de la pharmacopée traditionnelles et qui soient disponibles pour le plus grand nombre. Ainsi avons-nous évalué les effets d'un extrait de propolis, une résine végétale de la ruche produite par les abeilles et constituée majoritairement de flavonoïdes, sur la survie des cellules LNCaP.

Après $48 \mathrm{H}$ de traitement la propolis bloque la survie des cellules (test au MTT) avec à une IC50 égale à $0,05 \mathrm{mg} / \mathrm{ml}$. Un effet anti-apoptotique est visualisé par l'augmentation de l'accumulation de PARPc mesurée en western blot. De façon intéressante, la propolis diminue significativement l'accumulation du récepteur des androgènes après 4h de traitement. La mesure du PSA secrétée dans le milieu de culture par les cellules $\mathrm{LNCaP}$ a montré aussi une diminution significative de sa concentration à partir de la $4^{\text {ème }}$ heure suivant le traitement.

Cette étude montre que l'extrait de propolis agit sur la survie des cellules LNCaP sans doute par un effet anti-androgène. Ce dernier doit être confirmé par des études de transfections transitoires en utilisant un gène rapporteur sous le contrôle des androgènes. 


\title{
En situation de catabolisme musculaire, les protéines de lactosérum ne permettent de contrecarrer, que transitoirement, la résistance anabolique
}

\author{
M Jarzaguet $^{(1,2)}$, A Revel ${ }^{(1,2)}$, C Migné $^{(3)}$, I Savary-Auzeloux $^{(1,2)}$, D Rémond ${ }^{(1,2)}$, \\ D Dardevet ${ }^{(1,2)}$
}

(1) Clermont Université, Université d'Auvergne, Unité de Nutrition Humaine, BP 10448, F-63000

Clermont-Ferrand

(2) INRA, UMR 1019, UNH, CRNH Auvergne, F-63000 Clermont-Ferrand

(3) INRA, UMR 1019, Plateforme d'Exploration du Métabolisme, UNH, F-63000 Clermont-

Ferrand, France

\section{dominique.dardevet@clermont.inra.fr}

\section{Introduction.}

L'atrophie musculaire est la conséquence d'un déséquilibre du métabolisme des protéines musculaires. La plupart des états cataboliques sont caractérisés par une résistance du métabolisme protéique à l'insuline et aux acides aminés. II en résulte une inefficacité de la prise alimentaire pour générer une balance azotée positive pendant la période post-prandiale. Dans de telles situations, les protéines à digestion rapide et riches en leucine (i.e Lactosérum (LAC)) ont été montrées pour être plus efficaces que la caséine pour optimiser la stimulation de la protéosynthèse musculaire (PS). Cependant et paradoxalement, la masse musculaire est rarement préservée par des supplémentations en LAC. Notre hypothèse est que cette stimulation ne se produit que pendant une courte période de temps à l'état nourri mais qui reste insuffisante pour se traduire par une augmentation significative de la masse musculaire au long terme. Pour valider et vérifier cette hypothèse, une mesure cinétique de la PS et de la protéolyse (PRO) au niveau musculaire est nécessaire pendant toute la période post prandiale.

Matériels et Méthodes. Miniporcs ont été cathétérisés à la fois dans l'artère et la veine fémorales et infusés avec de la 13C Phe afin d'évaluer, toutes les $30 \mathrm{~min}$, la PS et PRO musculaires dans la patte arrière par la méthode de différence artério-veineuse en acides aminés et en traceur. Les animaux sont étudiés avant et après la prise du repas. L'état catabolique a été induit par un traitement aux glucocorticoïdes (déxamethasone (DEX) pendant 8j) et l'effet de 2 protéines, la caséine (CAS) et le LAC a été testé sur la PS et la PRO pendant 6,5h. Les différences entre groupes ont été évaluées par ANOVA en mesures répétées à 3 facteurs (type de protéines, traitement DEX, temps post prandial) et le seuil de signification à $\mathrm{P}<0.05$.

Résultats. Après DEX, les animaux sont, au niveau musculaire, en bilan azoté négatif en PA (contrôles vs DEX) et l'apport en protéines sous forme de CAS ne permets pas de passer en bilan azoté positif (CAS vs CAS DEX; la PRO restant supérieure à la PS). Avec le régime LAC, les animaux traités sont en mesure de générer une balance azotée musculaire positive pendant les 120 premières min (PS:+40\% et PRO: $-20 \% ; \mathrm{P}<0.05)$ ) mais qui disparait par la suite jusqu'à la fin de la période postprandiale. Les glucocorticoïdes sont associés à une résistance à l'insuline (augmentation de l'insuline/glycémie sous CAS). Nourris avec du LAC, les animaux présentent toujours une hyperinsulinémie (LAC vs LAC DEX) mais la glycémie postprandiale est normalisée.

Conclusions. Le LAC a bien été plus efficace pour générer un bilan azoté musculaire positif dans cet état catabolique mais celui-ci a été de courte durée ce qui conforte notre hypothèse sur son efficacité sur la perte de masse musculaire. Les stratégies nutritionnelles doivent donc être optimisées pour augmenter la durée de l'efficacité du LAC dans les états cataboliques. En revanche, le LAC en soit est intéressant pour contrôler l'hyperglycémie prandiale dans les situations cataboliques où une résistance à l'insuline du métabolisme du glucose est souvent associée. 


\title{
P10
}

\section{Exosomes : New mediators of host response to Crohn's disease- associated adherent-invasive Escherichia coli}

\author{
J Carrière, A Bretin, N Barnich, A Darfeuille-Michaud, H Thi Thu Nguyen \\ UMR 1071 Inserm, University of Auvergne, Clermont-Ferrand 63000, France \\ Jessica.carriere@udamail.fr
}

Crohn's disease $(C D)$ is a chronic inflammatory bowel disease of which the etiology involves environmental, genetic and microbial factors. Our group and others have shown a high prevalence of the invasive Escherichia coli strains, designated adherent-invasive E. coli (AIEC), in the intestinal mucosa of CD patients. Exosomes are small endosomal-derived vesicles involved in cell to cell communication and have been implicated in various diseases including cancer and infectious disorders. It has been reported that mammalian cells infected with pathogens can release exosomes containing microbial compounds. Here, we investigated the capacity of CD-associated AIEC bacteria to induce secretion of exosomes by intestinal epithelial cells and to determine the inflammatory characteristics of the released exosomes.

Electron microscopy and immunogold-labeling analyses for $\mathrm{CD63}$, an exosomal marker, showed that differentiated T84 cells infected with AIEC LF82 secreted an increased amount of exosomes compared to uninfected cells. This was confirmed by increased levels of CD63 as assessed by Western blot. Stimulation of human macrophages with exosomes secreted by LF82-infected T84 cells, but not by uninfected cells, significantly induced production of the proinflammatory cytokines TNF-alpha and IL-6, and this was not due to the presence of lipopolysaccharide, known to induce a pro-inflammatory response. Mass spectrometry analysis revealed that exosomes released by T84 cells upon LF82 infection carried microbial antigens such as the outer membrane protein $\mathrm{C}$, known to be involved in AIEC adhesion and invasion. Our study shows that in response to CD-associated AIEC infection, intestinal epithelial cells release exosomes that can trigger pro-inflammatory responses in naïve macrophagic recipient cells. 


\title{
P11
}

\section{Mise en évidence de l'interaction TIP60-H3K4ac dans le cancer sporadique du sein}

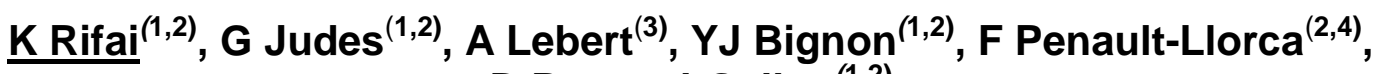 \\ D Bernard-Gallon ${ }^{(1,2)}$
}

(1) Département d'Oncogénétique, Centre Jean Perrin, CBRV, 28 place Henri Dunant, 63001, Clermont-Ferrand, France

(2) EA 4677 "ERTICA", Université d'Auvergne, 63011, Clermont-Ferrand, France

(3) Université Blaise Pascal, Institut Pascal, UMR 6602 CNRS/UBP, 63177, Aubière, France

(4) Laboratoire de Pathologie, Centre Jean Perrin, 63011, Clermont-Ferrand, France

\section{k.rifaii@live.com}

Le cancer du sein est le cancer le plus fréquent chez les femmes, il est aussi la cause principale de décès par cancer chez les femmes dans le monde. La complexité de la cancérogenèse ne peut pas être représentée par des altérations génétiques seules, mais implique aussi des modifications épigénétiques. L'épigénétique se réfère à l'étude des mécanismes qui modifient l'expression du gène sans altérer la séquence d'ADN primaire. La perturbation des processus épigénétiques peut conduire à l'altération de la fonction du gène et à la transformation en cellule maligne. Les altérations épigénétiques comprennent, entre autres, les changements dans la méthylation de l'ADN et les modifications des histones. Ainsi, la modification post-traductionnelle des histones est un autre processus épigénétique qui peut expliquer le comportement des cellules tumorales. Nous nous sommes intéressés dans cette étude à la marque H3K4ac. Les études effectuées précédemment dans notre laboratoire, ont montré une diminution significative du dépôt de H3K4ac dans les tumeurs du sein, de plus, l'élément responsable de son dépôt n'a pas été encore identifié chez l'homme. TIP60 est une histone acétyltransférase, qui est aussi sous-exprimée dans le cancer du sein, son orthologue chez la levure est connu pour déposer la marque H3K4ac. Dans ce travail, on a mis en évidence une interaction physique et une colocalisation entre TIP60 et H3k4ac sur les promoteurs de 7 gènes dérégulés dans le cancer sporadique du sein (ERa, ERß,EZH2, BRCA1, SRC3, P300 et PGR). Ainsi la diminution de l'expression de TIP60 entraine une diminution du dépôt de la marque H3K4ac, qui pourrait jouer un rôle dans la dérégulation de l'expression du panel de 7 gènes étudiés. 


\title{
P12
}

\section{Combinatorial effects of western diet and adherent-invasive E. coli infection on intestinal inflammation}

\author{
A Agus $^{(1)}, J_{\text {Denizot }}^{(1)}, J$ Thevenot ${ }^{(1,2)}$, M Martinez-Medina $^{(1)}, \mathrm{S} \mathrm{Massier}^{(1)}$, P Sauvanet $^{(1)}$, \\ A Bernalier-Donadille ${ }^{(3)}$, S Denis ${ }^{(2)}$, P Hofman $^{(4)}$, R Bonnet ${ }^{(1,5)}$ E Billard $^{(1,6)}$, N Barnich $^{(1,6)}$
}

(1) Clermont Université, M2iSH, UMR 1071 INSERM/Université d'Auvergne, Clermont-Ferrand, France Unité Sous Contrat 2018 Institut National de la Recherche Agronomique, Clermont-Ferrand, France

(2) Clermont Université, Université d'Auvergne, Centre de Recherche en Nutrition Humaine Auvergne, EA 4678 CIDAM, Conception Ingénierie et Développement de l'Aliment et du Médicament, ClermontFerrand, France

(3) UR454 Microbiology Division, INRA, Research Centre of Clermont-Ferrand-Theix, 63122 Saint Genès-Champanelle, France

(4) Laboratory of Clinical and Experimental Pathology and Hospital-Related Biobank (BB 0033-00025), Pasteur Hospital, and IRCAN CNRS UMR 7284, Inserm U1081, Nice Sophia Antipolis University,

France

(5) Centre Hospitalier Universitaire, Clermont-Ferrand 63000, France

(6) Institut Universitaire de Technologie, Génie Biologique, Aubière, France

\section{Alison.agus@udamail.fr}

Recent advances have shown that the abnormal inflammatory response observed in Crohn's disease (CD) involves an interplay between intestinal microbiota, host genetics and environmental factors. The escalating consumption of fat and sugar in Western countries parallels an increased incidence of CD during the latter 20th century. The impact of a HighFat/High-Sugar (HF/HS) diet in mice was evaluated regarding gut homeostasis. HF/HS diet increased Lcn-2 level in stools from 5 weeks until 18 weeks of treatment, showing that HF/HS diet creates a specific inflammatory environment in the gut. This was correlated with intestinal mucosa dysbiosis characterized by reduction of bacterial richness, but also by an overgrowth of pro-inflammatory proteobacteria such as E. coli and a decrease in protective bacteria. In addition, the fecal transplantation from HF/HS treated mice to germ-free mice increased susceptibility to Adherent-Invasive Escherichia coli (AIEC) infection. Interestingly, HF/HS diet led to an exacerbation of gut inflammation following DSS-induced colitis, with an increase of DAI, histological score and release of pro-inflammatory cytokines. Moreover, a significantly decrease of SCFA concentrations in fecal samples from mice fed a HF/HS diet compared with mice fed a conventional diet was observed. The expression of SCFA G-protein coupled receptor 43 (GPR43) was reduced in mice treated with a HF/HS diet and reduced in CD patients compared with controls. Interestingly, mice treated with an agonist of GPR43 were protected against DSS-induced colitis. Western diet creates a low-grade inflammation in the gut with a decrease of protective SCFA producing bacteria, favoring the overgrowth of opportunistic pathogenic E. coli. Moreover, activation of GPR43 receptor pathway could be used as a new strategy to treat CD patients abnormally colonized by AIEC bacteria. 


\title{
P13
}

\section{FoodComEx : une chimiothèque internationale pour les composés dérivés de l'alimentation}

\author{
D Wishart ${ }^{(1)}$, C Weinert $^{(2)}$, E pujos Guillot ${ }^{(3,4)}$, M Ulaszewska $^{(5)}$, F Giacomoni $^{(3,4)}$, \\ F Mattivi ${ }^{(5)}$, M Urpi-Sarda ${ }^{(6)}$, C Andres-Lacueva ${ }^{(6)}$, SE Kulling ${ }^{(2)}$, LO Dragsted ${ }^{(7)}$, \\ $\underline{\text { C Manach }}{ }^{(3,4)}$
}

(1) Univ. Alberta, Edmonton, Canada

(2) Max Rubner-Institut, Karlsruhe, Germany

(3) INRA, UMR 1019, UNH, CRNH Auvergne, F-63000 Clermont-Ferrand, France

(4)Clermont Université, Université d'Auvergne, Unité de Nutrition Humaine, BP 10448, F-63000

Clermont-Ferrand, France

(5) Fondazione Edmund Mach, San Michele all'Adige, Italy

(6) Univ. Barcelona, Spain

(7) Univ. Copenhagen, Denmark

claudine.manach@clermont.inra.fr

Le manque de standards commerciaux pour de nombreux composés dérivés de l'alimentation, en particulier les métabolites retrouvés dans le sang et les tissus chez l'homme après consommation des aliments constitue une limitation importante en nutrition. Par exemple l'identification de centaines de métabolites détectés dans les profils métabolomiques reste difficile sans standard, d'autre part les études mécanistiques sur modèles cellulaires se font encore trop souvent avec des composés qui ne sont pas ceux retrouvés au niveau physiologique. FoodComEx (Food Compound Exchange, http://foodcomex.org/) est une nouvelle chimiothèque initiée dans le cadre du projet européen FoodBAll pour faciliter l'accès à des molécules dérivées de l'alimentation qui sont aujourd'hui peu ou pas disponibles. Dans le cadre de projets divers, beaucoup de composés ont été produits à petite échelle dans des laboratoires académiques, par synthèse chimique ou enzymatique, par purification à partir de matrices biologiques ou encore par incubation avec des microorganismes. Des collections entières de composés précieux dorment dans des laboratoires du monde entier. L'objectif de FoodComEx est de mettre à disposition ces composés pour une large communauté d'utilisateurs. FoodComEx sera un catalogue interrogeable en ligne des composés disponibles, indiquant les coordonnées du laboratoire offrant de partager chaque composé. Tout utilisateur intéressé contactera directement le laboratoire producteur et les termes de la collaboration seront décidés par les deux partenaires, dans le cadre de la charte des bonnes pratiques de FoodComEx. Des données physico-chimiques, spectrales ainsi que des informations décrivant l'origine du composé, sa stabilité, sa pureté, etc seront disponibles dans la fiche de chaque composé. Les données analytiques seront enrichies continuellement par les utilisateurs. FoodComEx est une initiative récente qui bénéficie déjà du soutien de réseaux tels que la société allemande des food chemists et l'action COST POSITIVe. Tout laboratoire souhaitant partager des composés dérivés de l'alimentation est évidemment le bienvenu pour enrichir la collection de FoodComEx et permettre de nouvelles collaborations. Financement : Projet FoodBall JPI HDHL. 


\title{
P14
}

\section{Impact d'une dysbiose intestinale sur l'hypersensibilité viscérale d'origine colique en modèle murin}

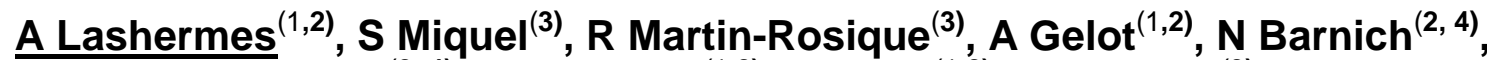 \\ A Darfeuille-Michaud $^{(2,4)}$, A Eschalier ${ }^{(1,2)}$, D Ardid $^{(1,2)}$, M Thomas $^{(3)}$, P Langella $^{(3)}$, \\ FA Carvalho ${ }^{(1,2)}$
}

(1) INSERM 1107 Neuro-Dol, Clermont-Ferrand, France

(2) Université d'Auvergne, Clermont-Ferrand, France

(3) INRA UMR1319 Micalis, Jouy-en-Josas, France

(4) INSERM 1070 M2ISH, Clermont-Ferrand, France

\section{Amandine.LASHERMES@udamail.fr}

L'hypersensibilité viscérale d'origine colique (HSVC) est un symptôme fréquemment observé chez les patients souffrant du Syndrome de l'Intestin Irritable (SII) ou de Maladies Inflammatoires Chroniques Intestinales (MICI). Ces atteintes intestinales sont caractérisées par une rupture de l'homéostasie entre le microbiote et le système immunitaire de l'hôte. En effet, plusieurs études ont décrit une dysbiose intestinale chez ces patients : (1) une colonisation anormale de la muqueuse iléale de patients atteints de la Maladie de Crohn (MC) par des Escherichia coli Adhérentes et Invasives (AIEC) associée à une surexpression du récepteur de colonisation bactérienne CEACAM6, ou (2) une diminution de l'abondance de Faecalibacterium prausnitizii, une bactérie commensale possédant des propriétés antiinflammatoires. Dans ce contexte, l'objectif de ce travail a été d'étudier l'impact des AIEC et de F. prausnitzii sur l'HSVC en modèle murin.

L'infection de souris transgéniques exprimant le récepteur humain CEACAM6 par des bactéries AIEC (souche de référence LF82) induit une HSVC associée à une inflammation intestinale à bas bruit et une augmentation de la perméabilité intestinale. Cette HSVC persiste après élimination des bactéries et rétablissement de l'homéostasie intestinale. D'autre part, un traitement par gavage avec F. prausnitzii permet de restaurer une sensibilité colique ainsi qu'une perméabilité intestinale normale dans un modèle murin d'HSVC non-inflammatoire induit par séparation maternelle néonatale.

Ces résultats montrent ainsi qu'une dysbiose intestinale peut impacter sur la sensibilité colique, avec (1) une implication directe des AIEC associées à la MC dans une HSVC et (2) un rôle protecteur de F. prausnitzii dans un modèle d'HSVC non-inflammatoire. 


\title{
P15
}

\section{PhytoHub : une base de données pour les études métabolomiques sur les bioactifs végétaux}

\author{
F Giacomoni ${ }^{(1,2)}$, Y Fillâtre ${ }^{(1,2)}$, JA Rothwell $^{(1,2)}$, R Eisner $^{(3)}$, E Pujos-Guillot $^{(1,2)}$, C Knox $^{(3)}$, \\ C Manach $^{(1,2)}$
}

(1) INRA, UMR 1019, UNH, CRNH Auvergne, F-63000 Clermont-Ferrand, France

(2) Clermont Université, Université d'Auvergne, Unité de Nutrition Humaine, BP 10448, F-63000

Clermont-Ferrand, France

(3) In Siliflo Inc, Edmonton, Canada

claudine.manach@clermont.inra.fr

Au cours des dernières années les preuves de l'activité des bioactifs végétaux dans la prévention des maladies cardiovasculaires se sont accumulées, avec de nombreuses études d'intervention contrôlées et randomisées. Cependant l'exposition interne des sujets aux métabolites de bioactifs végétaux est insuffisamment caractérisée. Elle dépend à la fois des consommations alimentaires et des capacités d'absorption et de métabolisme de chacun, qui varient par exemple en fonction de la composition du microbiote intestinal. La métabolomique basée sur la spectrométrie de masse offre la possibilité de caractériser ces expositions individuelles de manière très détaillée, en intégrant des métabolites jusqu'ici peu considérés. La mise en relation des profils complets d'exposition aux bioactifs avec les réponses enregistrées dans les études cliniques au niveau vasculaire permettra d'identifier les métabolites de bioactifs les plus importants et d'aller vers une meilleure compréhension des variations inter-individuelles de réponse à la consommation de produits végétaux protecteurs. PhytoHub (www.phytohub.eu) est une base de données en ligne qui facilitera l'utilisation de la métabolomique pour la caractérisation des expositions individuelles aux bioactifs végétaux. Elle rassemble des donnés physico-chimiques, de sources alimentaires, de métabolites connus ou prédits, ainsi que des données spectrales pour l'ensemble des bioactifs présents dans les aliments végétaux consommés régulièrement ( $F \& L$, céréales et graines, épices, thé ou café,...). PhytoHub 1.0 contient les 240 terpènes les plus consommés et tous leurs métabolites connus chez l'homme, d'après une revue extensive de la littérature. PhytoHub sera mise à jour régulièrement, grâce à la collaboration d'un grand réseau de collaborateurs spécialistes des différents bioactifs végétaux. En particulier les polyphénols vont être ajoutés très prochainement grâce à la contribution de l'action COST POSITIVe (http://www6.inra.fr/cost-positive), qui est aujourd'hui le plus grand réseau international sur les bioactifs végétaux.

PhytoHub est une initiative ouverte. Les personnes souhaitant y collaborer peuvent nous contacter.

Financement : Projet ANR ALIA-007-PhenoMeNEp; Projet FoodBall JPI HDHL; Bourse post-doc Region Auvergne/FEDER pour Y. Fillâtre. 


\title{
P16
}

\section{Etude clinique : Expression des canaux ioniques Cav et ASIC dans la muqueuse colique}

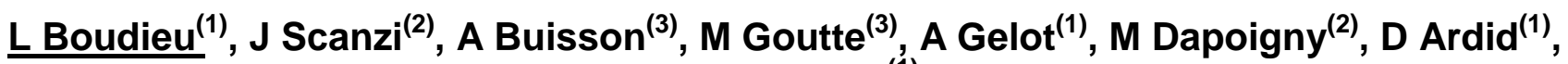 \\ FA Carvalho ${ }^{(1)}$
}

(1) UMR1107 Inserm/ Université d'Auvergne NeuroDol, Laboratoire de pharmacologie fondamentale et clinique de la douleur, Clermont-Ferrand

(2) Service de médecine digestive et hépatobiliaire, CHU Estaing, Clermont-Ferrand

(3) Service commun pole digestif et hépatobiliaire, Clermont-Ferrand, France UMR 1071 Inserm/Université d'Auvergne; USC-INRA 2018, Clermont-Ferrand, France

\section{lu.boudieu@gmail.com}

L'inflammation de la muqueuse colique est un des mécanismes à l'origine des douleurs abdominales associées aux maladies inflammatoires chroniques de l'intestin ( $\mathrm{MICl}$ ) et plus particulièrement de la rectocolite hémorragique $(\mathrm{RCH})$. En effet, la présence d'une inflammation intestinale à bas bruit pendant les périodes de rémission de ces $\mathrm{MICl}$ pourrait être responsable d'une sensibilisation des fibres nerveuses innervant le côlon et dont l'excitabilité dépend d'un certain nombre de canaux ioniques. Le but de cette étude est donc de confirmer le potentiel des canaux calciques voltage-dépendants (Cav), et de canaux sodiques sensibles au pH (ASIC), en tant que nouvelles cibles d'intérêt thérapeutique pour la prise en charge de l'inflammation intestinale à bas bruit et des douleurs associées observées lors des périodes de rémission chez des patients souffrant de $\mathrm{MICl}$.

$\mathrm{Au}$ stade préclinique, lors de l'induction d'une hypersensibilité colique inflammatoire permettant de mimer la douleur viscérale chez l'animal, la surexpression de la sous-unité alpha2-delta1 des canaux calciques voltage-dépendants Cav a été mise en évidence au niveau colique. Toujours chez l'animal, le blocage pharmacologique de ces canaux permet de diminuer l'inflammation et la sensibilité colique associée. Des données similaires ont été obtenues concernant les canaux sodiques ASIC. De plus, une étude clinique récemment menée sur des patients souffrant d'une autre atteinte intestinale, le syndrome de l'intestin irritable (SII), a mis en évidence une surexpression du canal calcique voltage-dépendants Cav3.2 spécifiquement chez les patients atteints de SII par rapport à des patients contrôles. L'objectif de cette étude est de rechercher une surexpression des canaux ioniques Cav et ASIC dans la muqueuse colique de patients atteints de $\mathrm{RCH}$ par rapport à des patients témoins. 


\title{
P17
}

\section{Effect of acute consumption Passiflora setacea juice on the monocyte adhesion to endothelial cells: a validation ex vivo study}

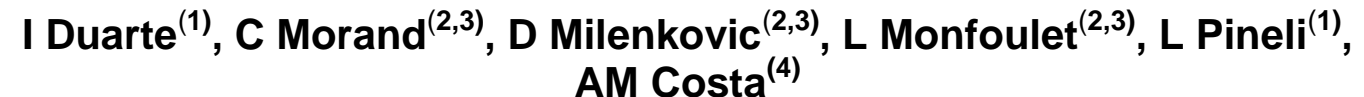 \\ (1) University of Brasilia, Graduate Program in Human Nutrition, Brazil \\ (2) INRA, UMR 1019, UNH, CRNH Auvergne, F-63000 Clermont-Ferrand, France \\ (3) Clermont Université, Université d'Auvergne, Unité de Nutrition Humaine, BP 10448, F-63000 C \\ Clermont-Ferrand, France, \\ (4) PASSITEC Network, Embrapa Cerrados, Brazil
}

ana-maria.costa@embrapa.br

The pulp of Passiflora setacea (PS), a wild species of Brazilian Savanna, has been recently shown to have higher levels of phenolic compounds, when compared to its commercial species. The leading cause of CVD is atherosclerosis and a diet rich in phenolic compounds may have some effects on monocyte adhesion. Therefore, the aim of the present study was to investigate effect of consumption of PS juice by healthy volunteers on the endothelial cell function, particularly on monocyte adhesion on TNF-alfa-activated endothelial cells.

Three middle-aged volunteers were included in a cross-sectional study to analyse the effect of $250 \mathrm{~mL}$ PS juice consumption. A pool of fasting serum samplings were performed before (t0h) and $3 \mathrm{~h}$ after the consumption (t3h). Primary human umbilical vein endothelial cells (HUVEC) were cultivated in an endothelial growth medium (EGM) with $25 \%$ of human serum (HS) for $7 \mathrm{~h}$ with a 4-hour-stimulation of $1 \mathrm{ng} / \mathrm{mL}$ of TNF-alfa. Monocytes (THP-1) were added and incubated for 15min with HUVEC. The number of THP1 per HUVEC was counted in microscopic fields.

In preliminary results, the treatment with TNF-alfa significantly increased cell adhesion compared with unstimulated control cells (a 3.93-fold increase). Pre-exposure of HUVEC to human serum sampled 3 hours after the consumption of PS juice significantly reduced monocyte adherence to TNF-alfa-activated endothelial cells from - 59 to - 43\% $(P<0,05)$. The decrease of monocytes adhesion to endothelial cells may indicate an anti-inflammatory and atheroprotective effects of PS juice consumption in healthy volunteers. 


\title{
P18
}

\section{Vascular and Nutrigenomic effects of grapefruit flavanones consumption: A RCT in post- menopausal women}

\author{
V Habauzit $^{(1,2,3)}$, D Milenkovic ${ }^{(1,2)}$, MA Verny $^{(1,2)}$, N Barber-Chamoux $^{(1,2,4)}$, C Bobby $^{(1,2)}$, \\ A Mazur ${ }^{(1,2)}$, C Dubray $^{(3)}$, C Morand $^{(1,2)}$ \\ (1) INRA, UMR 1019, UNH, CRNH Auvergne, F-63000 Clermont-Ferrand, France \\ (2) Clermont Université, Université d'Auvergne, Unité de Nutrition Humaine, BP 10448, F-63000 \\ Clermont-Ferrand, France \\ (3) Centre Investigation Clinique, CIC-CPC INSERM 501, Centre Hospitalier Universitaire, Clermont- \\ Ferrand, France \\ (4) Department of Cardiology, Gabriel Montpied Hospital, Clermont-Ferrand University Hospital, \\ Clermont-Ferrand, France

\section{christine.morand@clermont.inra.fr}

The consumption of citrus fruits is associated with health benefits. However, clinical data regarding the effects of grapefruit flavanone consumption on vascular function are lacking. The present clinical study aimed at 1) characterizing the specific role of naringin in the effect of a long-term consumption of grapefruit juice on vascular function in humans and 2) analyzing changes in PBMCs transcriptome profile induced by grapefruit naringin.

52 healthy post-menopausal women were enrolled in a crossover RCT. For two periods of 6 months, subjects consumed $340 \mathrm{ml} / \mathrm{d}$ of grapefruit juice (212mg naringin) or an iso-energetic matched control beverage without flavanones. The effects on endothelial function (FMD), arterial stiffness (PWV) and blood pressure as well as on systemic biomarkers of CV risk were evaluated. A global gene expression profiles in peripheral blood mononuclear cells was performed using microarrays.

PWV was significantly lower after consumption of grapefruit juice than after consumption of the matched control drink without flavanones. Whereas the other vascular parameters and conventional biomarkers associated to CV risks were not affected by the intervention. The PBMCs nutrigenomic analyses showed that the intake of naringin through grapefruit consumption regulated the expression of genes involved in inflammatory processes and in interactions between vascular and circulating immune cells.

This study showed that the long-term consumption of grapefruit juice could protect from arterial stiffening in humans. This effect may be related to flavanones. The nutrigenomic study revealed that grapefruit flavanones might be effective in reducing the interactions between immune cells and vascular endothelium. Inflammation and immune cell infiltration are known for their role in the induction of arterial stiffness. 


\title{
P19
}

\section{DHA-supplementation prior to fasting prevents muscle atrophy in mice}

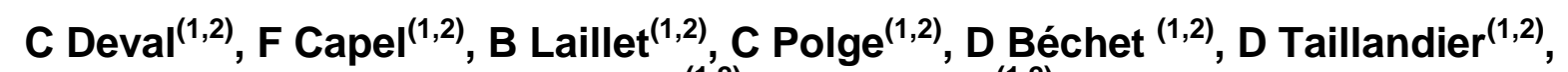 \\ D Attaix ${ }^{(1,2)}$, L Combaret $^{(1,2)}$
}

(1) Clermont Université, Université d'Auvergne, Unité de Nutrition Humaine, BP 10448, F-63000

Clermont-Ferrand

(2) INRA, UMR 1019, UNH, CRNH Auvergne, F-63000 Clermont-Ferrand

\section{lydie.combaret@clermont.inra.fr}

Muscle wasting prevails in numerous diseases (e.g. diabetes, cardiovascular and kidney diseases, COPD,...$)$ and increases healthcare costs. A major clinical issue is to devise new strategies preventing muscle wasting. We hypothesized that a long-term docosahexaenoic acid (DHA) supplementation prior to fasting may preserve muscle mass in vivo.

Six-wk-old C57BL/6 mice were fed a DHA-enriched or a control diet for 8 weeks and then fasted for $48 \mathrm{~h}$. The effect of DHA on i) muscle energy stores (glycogen, triglycerides (TG)), ii) muscle mass, and iii) Akt and AMPK signaling pathways involved in the control of protein and energy metabolism has been addressed.

The regulation of the formation and the fate of lipid stores have been also evaluated. Feeding mice a DHA-enriched diet prior to fasting elevated muscle glycogen contents without any change in TG levels, reduced muscle wasting, blocked the $55 \%$ decrease in Akt phosphorylation, and reduced by $30-40 \%$ the activation of AMPK, ubiquitination or autophagy. The DHA-enriched diet fully abolished the fasting induced-mRNA over-expression of the endocannabinoid receptor-1. Finally, DHA prevented or modulated the fasting-dependent increase in muscle mRNA levels for Rab18, PLD1 and perilipins, which determine the formation and fate of lipid droplets, in parallel with muscle sparing.

These data suggest that long-term DHA supplementation increased energy stores that can be efficiently mobilized, and thus preserved muscle mass in response to fasting through the regulation of Akt- and AMPK-dependent signaling pathways for reducing proteolysis activation. Whether a nutritional strategy aiming at increasing energy status may shorten recovery periods in clinical settings remains to be tested. 


\title{
Pathway-27: Etude Pilote sur les effets de substances bioactives en lien avec des marqueurs du Syndrome Métabolique
}

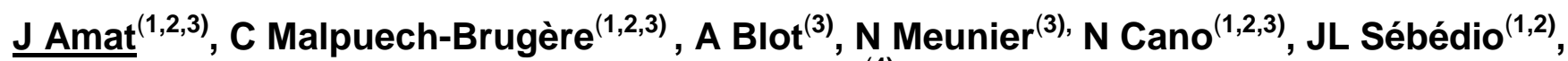 \\ A Bordoni ${ }^{(4)}$ \\ Au titre du consortium Pathway-27 Grant agreement no. 3118761
}

(3) INRA, UMR 1019, UNH, CRNH Auvergne, F-63000 Clermont-Ferrand, France

(4) Clermont Université, Université d'Auvergne, Unité de Nutrition Humaine, BP 10448, F63000 Clermont-Ferrand, France

(5) CRNH-Auvergne, CHRU-Clermont-Ferrand, France ;

(6) Dipartimento di Scienze e Tecnologie Agro-Alimentari, Università di Bologna, Bologne, Italie

\section{julien.amat@clermont.inra.fr}

\section{Introduction et but de l'étude :}

Le projet Pathway-27 permettra d'évaluer l'efficacité de l'acide docosahexaénoïque (DHA), seul ou en combinaison avec deux autres composés bioactifs (B-glucane (BG) et anthocyanes $(\mathrm{AC})$ ), dans la réduction des facteurs de risque du Syndrome Métabolique (SM). Ces composés dits « bioactifs » (BEF) ont été incorporés dans 3 matrices alimentaires différentes (produits laitiers, produits céréaliers et produits à base d'œufs) seuls ou en association DHA +/- BG ou DHA +/- AC.

L'objectif est d'appréhender les synergies possibles et les interactions BEF - matrice. Ces différentes matrices seront utilisées lors d'une étude d'intervention nutritionnelle multicentrique. Le but de cette étude européenne, randomisée, en double aveugle, est d'identifier le BEF qui induit une modification la plus favorable des paramètres lipidiques. Le BEF sélectionné sera ensuite testé sur une cohorte de huit cents sujets.

\section{Matériel et méthodes :}

Soixante-dix hommes et femmes à risque de SM ont été recrutés au Centre de Recherche en Nutrition Humaine Auvergne (CRNH-Auvergne) de Clermont-Ferrand (France). Les volontaires ont été divisés en 5 groupes recevant, pendant 4 semaines, une matrice alimentaire enrichie en DHA, BG, ou AC seul ou en association. Les marqueurs cliniques du SM ont été mesurés. De plus, des approches « omiques » seront utilisées pour examiner les changements métaboliques et potentiellement identifier de nouveaux marqueurs d'effets.

\section{Conclusion :}

Les résultats obtenus permettront de comprendre l'effet matrice sur la bioactivité des nutriments testés. 


\title{
P21
}

\section{L'EPA prévient l'insulino-résistance et l'intolérance au glucose chez la souris sous régime hyperlipidique et hypersucré}

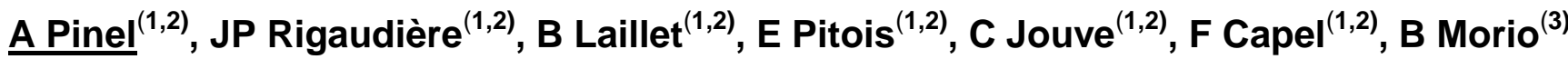 \\ (1) INRA, UMR 1019, UNH, CRNH Auvergne, F-63000 Clermont-Ferrand, France \\ (2) Clermont Université, Université d'Auvergne, Unité de Nutrition Humaine, BP 10448, F- \\ 63000 Clermont-Ferrand, France \\ (3) Institut CarMeN Lyon, France

\section{frederic.capel@clermont.inra.fr}

L'insulino-résistance $(\mathrm{IR})$ est une conséquence majeure de l'obésité. Elle favorise la progression du syndrome métabolique (SMet) et augmente le risque de diabète de type 2 et de maladies cardiovasculaires. L'IR est la résultante de désordres métaboliques causés par l'accumulation ectopique de graisse dans les tissus musculaires et hépatiques suite à une altération du stockage de ces graisses dans le tissu adipeux. Des stratégies nutritionnelles utilisant les acides gras polyinsaturés oméga-3 ont été proposées pour prévenir l'IR et le SMet associés à l'obésité par des mécanismes encore mal connus.

Le but de ce travail était de comparer les effets de trois oméga-3 (ALA, EPA et DHA) sur l'IR et les dysfonctions métaboliques durant un régime riche en lipides ( $45 \%$ de l'apport énergétique) et en sucrose (17\% de l'apport énergétique) chez la souris après 16 semaines de régime. L'IR a ensuite été évaluée par injection intra péritonéale (ip) d'insuline et suivi de la glycémie pendant 2 heures. La tolérance au glucose a été évaluée de manière similaire suite à l'injection ip de glucose.

Après 16 semaines, les régimes enrichis en ALA, EPA ou DHA n'ont pas influencé le poids ou l'apport calorique des animaux en comparaison avec le régime non enrichi en oméga-3. Cependant, I'EPA a réduit la concentration plasmatique en AG libres et en cholestérol total. L'EPA a également amélioré la sensibilité à l'insuline et la tolérance au glucose au niveau corps entier. Au contraire, L'ALA et le DHA n'ont eu aucun effet sur ces paramètres.

En conclusion, les acides gras oméga-3 ont des effets distincts sur l'insulino-résistance et l'intolérance au glucose induites par un régime riche en lipides et en sucrose. Contrairement à l'ALA et au DHA, I'EPA a un effet protecteur vis-à-vis de paramètres clés du syndrome métabolique. 

